UNIVERSITÉ DU QUÉBEC

MÉMOIRE PRÉSENTÉ À

L'UNIVERSITÉ DU QUÉBEC À CHICOUTIMI

COMME EXIGENCE PARTIELLE

DE LA MAÎTRISE EN RESSOURCES RENOUVELABLES

Par

MARIE-EVE BRADETTE HÉBERT

B. Sc. CHIMIE

ÉTUDE DU POTENTIEL BIOPHARMACEUTIQUE DU

Solidago canadensis Linné

MAI 2008 


\section{Bibliothèque}

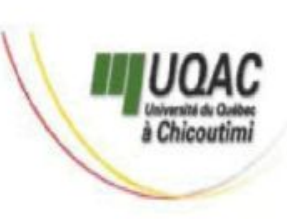

\section{Mise en garde/Advice}

Afin de rendre accessible au plus Motivated by a desire to make the grand nombre le résultat des results of its graduate students' travaux de recherche menés par ses research accessible to all, and in étudiants gradués et dans l'esprit des accordance with the rules règles qui régissent le dépôt et la governing the acceptation and diffusion des mémoires et thèses diffusion of dissertations and produits dans cette Institution, theses in this Institution, the I'Université du Québec à Université du Québec à Chicoutimi (UQAC) est fière de Chicoutimi (UQAC) is proud to rendre accessible une version make a complete version of this complète et gratuite de cette œuvre. work available at no cost to the reader.

L'auteur conserve néanmoins la The author retains ownership of the propriété du droit d'auteur qui copyright of this dissertation or protège ce mémoire ou cette thèse. thesis. Neither the dissertation or Ni le mémoire ou la thèse ni des thesis, nor substantial extracts from extraits substantiels de ceux-ci ne it, may be printed or otherwise peuvent être imprimés ou autrement reproduced without the author's reproduits sans son autorisation. permission. 


\section{RÉSUMÉ}

L'objectif principal de ce projet de recherche était de valoriser la biomasse de la forêt boréale notamment par l'étude du potentiel anti-inflammatoire d'extraits et de composés issus de la forêt boréale. Ainsi, des plantes potentiellement anti-inflammatoires de la forêt boréale ont été sélectionnées en se basant sur la médecine traditionnelle amérindienne. Les différentes parties (fleurs, feuilles, tiges et racines) des plantes sélectionnées ont été extraites par Soxhlet et les activités anti-inflammatoire, antioxydante et anticancéreuse des différents extraits ont été évaluées. Au cours de ce projet de maîtrise, il a été démontré que les fleurs de Solidago canadensis possèdent une activité anti-inflammatoire. De plus, les fleurs, les feuilles et les tiges de Solidago canadensis ont montré une activité antioxydante. Par conséquent, ces résultats supportent l'utilisation ethnopharmacologique de cette plante par les peuples ancestraux de l'Amérique du Nord. L'extrait de fleurs de Solidago canadensis a été sélectionné et les composés majoritaires de la fraction aqueuse ont été isolés par chromatographie et HPLC préparatif. La caractérisation par résonance magnétique nucléaire et par spectrométrie de masse a mené à l'identification de ces composés. De la sorte, cinq dérivés connus d'acide caffeoylquinique ont été isolés : l'acide 3-O-caffeoylquinique (acide néochlorogénique), l'acide 5-O-caffeoylquinique (acide chlorogénique), l'acide 4,5-di- $O$-caffeoylquinique, l'acide 3,5-di- $O$-caffeoylquinique et l'acide 3,4-di-O-caffeoylquinique. Toutefois, il s'avère que ces composés ne sont pas responsables de l'activité anti-inflammatoire observée pour l'extrait. Au cours de ce projet, 1'acide 3,4-di-O-caffeoylquinique a été rapporté pour la première fois à partir du Solidago canadensis. Également, les travaux de séparation ont mené à l'isolation de la quercétine et du 9 $\alpha, 16 \xi$-dihydroxy-6-oxo-7,13-labdadièn-15,16-olide (solicanolide), un nouveau diterpène de la famille des labdanes. Ce nouveau composé a démontré une activité anticancéreuse intéressante sur les lignées cellulaires A-549, DLD-1 et WS1. Cependant, les autres composés isolés se sont révélés inactifs. 


\section{REMERCIEMENTS}

Tout d'abord, je désire remercier mes codirecteurs, M. Jean Legault, Ph. D. et M. André Pichette, $\mathrm{Ph}$. D. de m'avoir permis de réaliser ce projet de maîtrise au sein de leur groupe de recherche. Au cours de ce projet, j'ai pu acquérir plusieurs connaissances au niveau scientifique ainsi que professionnel, qui constituent un atout de taille dans mon évolution personnelle.

Je tiens spécialement à remercier M. Vakhtang Mshvildadze, $\mathrm{Ph}$. D. pour avoir partagé son immense savoir en ce qui concerne la phytochimie, l'isolation et la culture géorgienne. Merci à M. Serge Lavoie, pour ses nombreux conseils, son support inestimable et le temps investi à satisfaire mes multiples requêtes et interrogations. Je remercie Mme Carole Grenon pour son appui incontestable, son éternelle patience et sa complicité. Merci à Mme Angélique Longtin pour l'évaluation de l'activité anti-inflammatoire, à M. Karl Girard Lalancette pour l'évaluation de l'activité antioxydante et à M. Maxime Lebrun pour l'évaluation de l'activité anticancéreuse. Merci également à tous ceux qui font partie de notre groupe de recherche et qui ont pu contribuer de près ou de loin à ce projet.

Je remercie Mme Karine Auclair, $\mathrm{Ph}$. D. de m'avoir accueillie au sein de son groupe de recherche lors de mon stage à l'Université McGill de Montréal. Cette expérience de travail en milieu anglophone constituait un défi de taille et s'est révélée largement profitable.

Merci à ma famille, à ceux qui croient en moi, qui me soutiennent et m'encouragent dans tout ce que j'entreprend. Je suis particulièrement reconnaissante envers mon conjoint, Vincent Auclair, qui par sa présence m'apporte l'énergie, la confiance et la motivation qui me permettent de mener à terme chacune de mes réalisations. Merci du fond du coeur! 


\section{TABLE DES MATIÈRES}

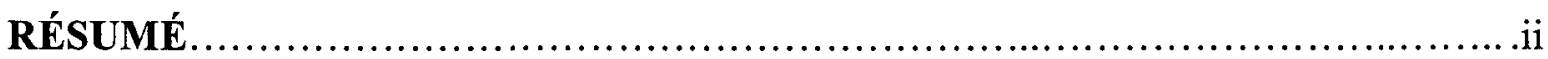

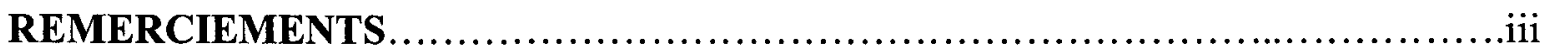

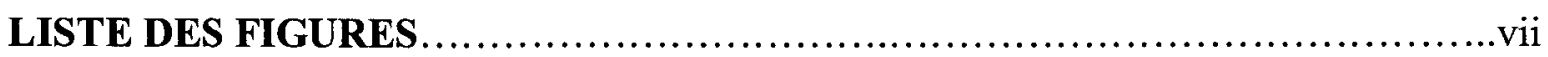

LISTE DES TABLEAUX ........................................................

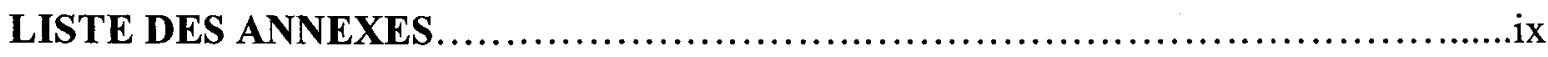

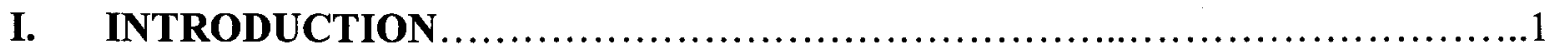

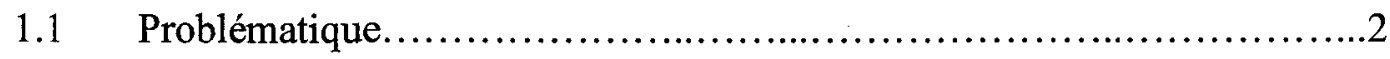

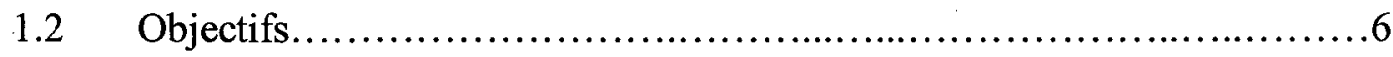

$1.3 \quad$ Structure du mémoire................................................

II. REVUE DE LITTÉRATURE : Solidago canadensis Linné........................8

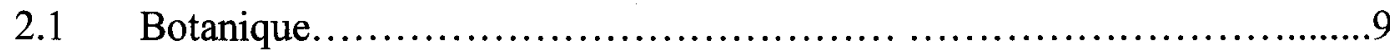

$2.2 \quad$ Usages.......................................................... 12

$2.3 \quad$ Phytochimie..........................................................

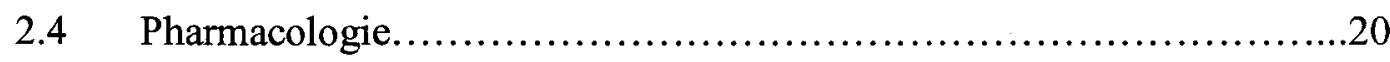

III. A New Labdane Diterpene from the Flowers of Solidago canadensis.............21 Article publié dans Chemical and Pharmaceutical Bulletin, 56 (1), 82-84, 2008.

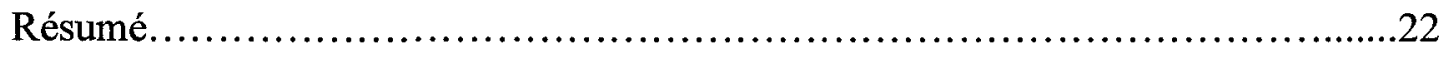

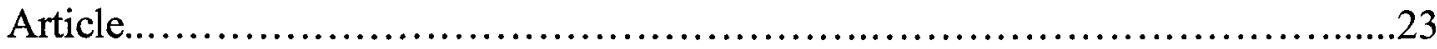




\section{Antioxidant and anti-inflammatory activities of methanol extracts from}

Solidago canadensis....................................................... 26

Article en préparation pour Journal of Ethnopharmacology.

Résumé..................................................................27

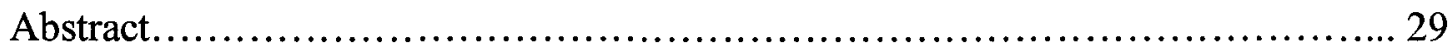

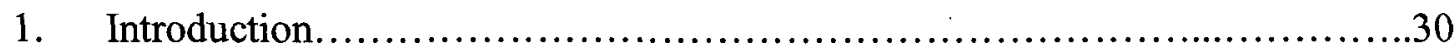

2. Materials and methods.................................................... 31

2.1 General experimental procedures.................................31

$2.2 \quad$ Plant material.................................................... 32

2.3 Extraction and isolation...........................................

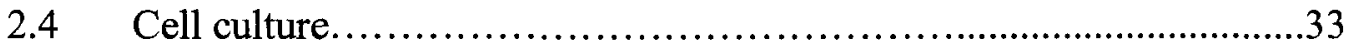

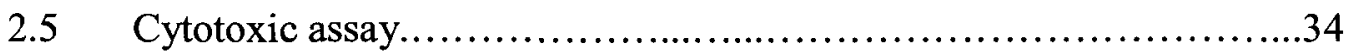

2.6 Measurement of the antioxidant activity by $\mathrm{ORAC}_{\mathrm{FL}}$ assay........... 34

2.7 Measurement of anti-inflammatory activity by nitric oxide (NO) inhibition on LPS-activated RAW 264.7 macrophages .................35

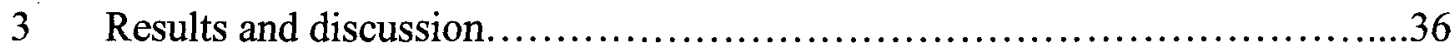

3.1 Extraction yields............................................. 36

3.2 Antioxidant activity of methanol extracts ........................36

3.3 Macrophages cytotoxicity and anti-inflammatory activity of extracts...37

3.4 Isolation of compounds from the flowers extract and evaluation of

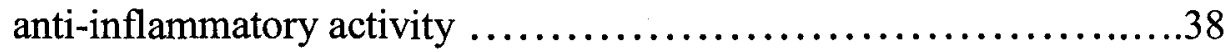

4. Acknowledgements.................................................. 39

5. References..........................................................40 


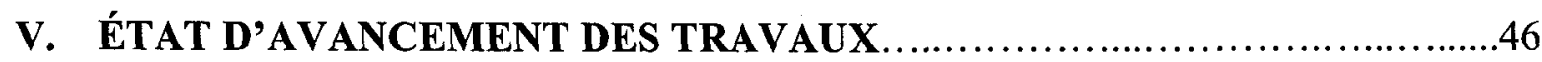

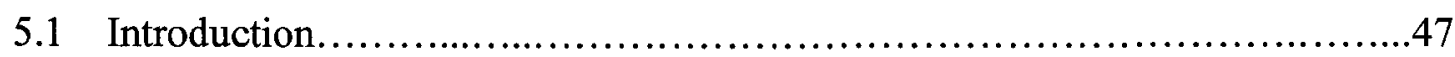

5.2 Préparation des espèces végétales........................................48

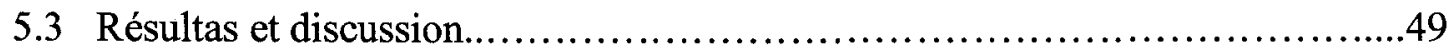

5.3.1 Évaluation de l'activité anti-inflammatoire............................49

5.3.2 Évaluation de l'activité antioxydante.............................50

5.3.3 Évaluation de l'activité anticancéreuse .................................51

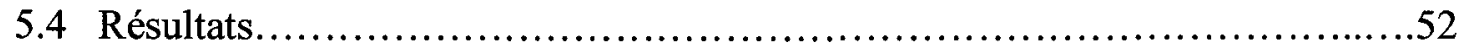

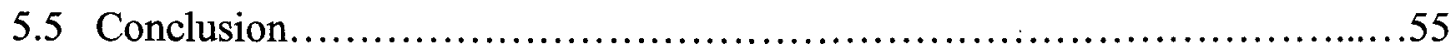

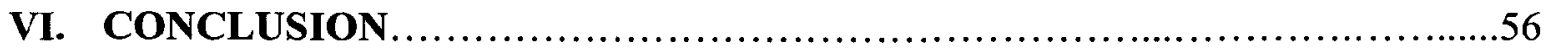

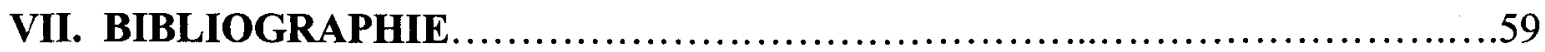

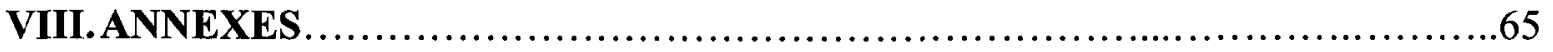




\section{LISTE DES FIGURES}

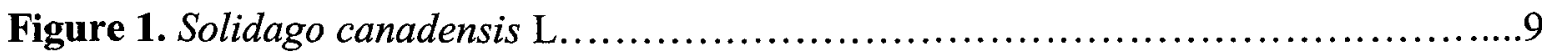

Figure 2. Distribution du Solidago canadensis L. en Amérique du Nord.................10

Figure 3. Structures des principaux constituants de l'huile essentielle de Solidago canadensis ................................................................ 13

Figure 4. Structures d'acides phénoliques présents dans le Solidago canadensis...........14

Figure 5. Structures de flavonoïdes provenant du Solidago canadensis...................15

Figure 6. Structures de diterpènes retrouvés dans le Solidago canadensis................16

Figure 7. Structures de diterpènes de type clérodane et de triterpènes de type lupane issus du Solidago canadensis......................................... 17

Figure 8. Structure de la génine des saponines isolées à partir du Solidago canadensis.....18

Figure 10. Structures des esters retrouvés dans le Solidago canadensis.................18

Figure 11. Structures des hydrocarbones et de l'époxide de caryophyllène provenant $\mathrm{du}$ Solidago canadensis............................................... 18

Figure 12. Structures de composés terpéniques isolés dans le Solidago canadensis.......19 


\section{LISTE DES TABLEAUX}

Tableau 1. Usages ethnopharmacologiques du Solidago canadensis en Amérique

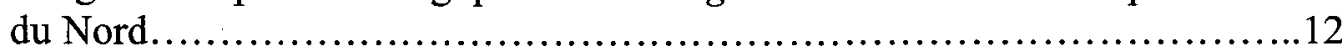

Tableau 2. Données relatives à la récolte des espèces sélectionnées......................48

Tableau 3. Évaluation de l'activité anti-inflammatoire d'espèces de la forêt boréale........52

Tableau 4. Évaluation de l'activité antioxydante d'espèces de la forêt boréale..............53

Tableau 5. Évaluation de l'activité anticancéreuse d'espèces de la forêt boréale.............54 


\section{LISTE DES ANNEXES}

ANNEXE 1. SPECTRE DE MASSE DU SOLICANOLIDE........................66

ANNEXE 2. SPECTRES RMN DU SOLICANOLIDE............................68

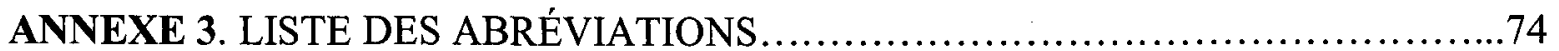


CHAPITRE I INTRODUCTION 


\section{Introduction}

\subsection{Problématique}

La forêt boréale est considérée comme l'un des plus vastes écosystèmes forestiers de la planète. Elle est surtout constituée de conifères et forme une bande ceinturant l'hémisphère Nord sur une largeur de plusieurs milliers de kilomètres. On la retrouve principalement au Canada, mais aussi en Russie et dans les pays scandinaves. Au Québec, elle couvre plus de $550000 \mathrm{~km}^{2}$, soit près de $70 \%$ du territoire forestier (Bryant et al, 1997). C'est un écosystème dynamique qui constitue à la fois un habitat pour la faune et la flore, un milieu de vie pour plusieurs communautés humaines et un réservoir de ressources naturelles renouvelables importantes.

En 2005, le gouvernement du Québec amorçait un véritable virage forestier en effectuant des modifications à la Loi sur les forêts. Des changements essentiels pour assurer la pérennité de la ressource forestière fondés sur le développement durable des régions. Une vision à long terme et une approche de prudence. Cependant, avec une réduction de $20 \%$ de la possibilité forestière pour les années 2005 à 2008, l'économie et le développement des régions sont particulièrement touchés (Ministère des ressources naturelles et de la faune, 2008). Ainsi, les régions tentent de diversifier l'exploitation de leurs forêts par le développement de nouveaux produits. Les produits ou sous-produits issus d'espèces 
végétales indigènes ou naturalisées autre que la matière ligneuse destinée à l'industrie du bois d'œuvre, de la pâte et papier, du bois de chauffage ou du charbon sont désignés comme étant des produits forestiers non ligneux (PFNL). Ces bioproduits constituent un outil pour la mise en place de communautés vivant de la forêt. Les PNFL sont une source d'emplois dans divers secteurs. Ils impliquent l'expertise et la culture locale et augmentent ainsi les retombées économiques par la diversification des produits de la forêt. Les PFNL sont utilisés au niveau alimentaire, cosmétique, ornemental, nutraceutique et pharmaceutique (Ministère des affaires municipales et des régions, 2007).

Autrefois, beaucoup d'espèces végétales étaient utilisées par les amérindiens pour traiter divers maux (Moerman, 1998). Cependant, peu d'études scientifiques ont porté sur l'efficacité réelle de ces plantes. En 2000, le nombre de médicaments sous ordonnance d'origine naturelle était évalué à $50 \%$. À ce jour, on estime à seulement $10 \%$ les espèces végétales qui auraient été étudiés pour leurs activités biologiques au niveau mondial. (Harvey, 2000).

L'asthme est la maladie respiratoire la plus importante au Canada. Au Québec, on estime à 700000 le nombre de personnes qui souffrent d'asthme dont 300000 enfants (Association pulmonaire du Québec, 2008). Même si les symptômes de cette maladie chronique peuvent être réduits en partie par un traitement adéquat, ceux-ci sont encore responsables d'une diminution importante de la qualité de vie. De plus, l'asthme est la cause d'une utilisation importante des soins de santé en milieu hospitalier imposant ainsi un 
fardeau important pour la société. Chaque année au Québec, l'asthme occasionne plus de 760000 visites chez le médecin, environ 100000 visites à l'urgence, 56000 jours d'hospitalisation, 3235 journées de travail perdues, 4000 appels pour des services ambulanciers et malheureusement près de 150 décès. On estime que l'asthme entraîne des coûts de plus de 150 millions de dollars chaque année pour le système de santé au Québec (Laberge et al., 2000).

L'asthme est une affection caractérisée par des symptômes paroxystiques ou persistants comme la dyspnée, l'oppression thoracique, la respiration sifflante, la production de mucus et la toux. Ces symptômes sont associés à une obstruction bronchique variable et à une hypersensibilité des voies aériennes à divers stimuli endogènes ou exogènes (Lemanske et Busse, 2003). L'inflammation et ses effets sur la structure des voies aériennes semblent être responsables des principaux mécanismes qui provoquent l'apparition et la persistance de l'asthme (Boulet et al., 1999). Dans des conditions normales, l'inflammation est un processus structuré issu des mécanismes de défense naturels. Son rôle est d'éliminer l'agent agresseur, de bloquer l'atteinte tissulaire et de rétablir l'homéostasie et la fonction du tissu (Lemanske et Busse, 2003). Cependant, il arrive que l'équilibre homéostatique soit rompu et qu'une anarchie dans le mécanisme de réparation provoque une chronicité de l'inflammation et par le fait même, une altération du fonctionnement des tissus. Les causes biologiques de ces dysfonctions font l'objet de plusieurs recherches, mais elles demeurent tout de même, peu connues. Jusqu'à maintenant, peu d'études cliniques visant le développement de thérapies pour l'asthme allergique ont eu pour cible les macrophages 
bronchiques. Les médiateurs de l'inflammation sont des substances naturelles présentes dans l'organisme qui déclenchent ou activent la réaction inflammatoire. Les cytokines sont des substances solubles de communication synthétisées par les cellules du système immunitaire ou par d'autres cellules, agissant à distance sur d'autres cellules pour en réguler l'activité et la fonction (Gosset et al., 1998). L'identification de composés d'origine naturelle issus de la forêt boréale ayant un effet sur la libération des médiateurs et des cytokines des macrophages pourrait permettre de bloquer le processus inflammatoire, freiner la dégradation de la muqueuse bronchique et les symptômes relatifs à l'asthme. De tels composés pourraient permettre de traiter les asthmatiques qui ne répondent pas aux traitements classiques (corticothérapie). D'autre part, ils pourraient également être utiles pour traiter d'autres maladies impliquant un processus inflammatoire comme l'arthrite et certaines maladies de l'intestin comme la maladie de Crohn. 


\subsection{Objectifs}

Plusieurs espèces de la forêt boréale étaient utilisées pour des applications antiinflammatoires par les peuples ancestraux d'Amérique du Nord. Ces espèces incluent Abies balsamea, Larix laricina, Ledum groenlandicum, Picea glauca, Picea mariana, Pinus banksiana, Populus balsamifera, Populus tremuloides, Solidago canadensis, Vaccinium angustifolium et Vaccinium myrtilloides (Moerman, 2000).

L'objectif principal de ce projet de recherche visait à valoriser la biomasse de la forêt boréale notamment par l'étude du potentiel anti-inflammatoire d'extraits et de composés issus de la forêt boréale. Les objectifs spécifiques de ce travail de recherche étaient de sélectionner plusieurs plantes potentiellement anti-inflammatoires de la forêt boréale en se basant sur la médecine traditionnelle amérindienne. Extraire les différentes parties (fleurs, feuilles, tiges et racines) des plantes sélectionnées. Évaluer les activités anti-inflammatoire, antioxydante et anticancéreuse des différents extraits. Sélectionner l'extrait le plus actif, isoler les composés responsables de l'activité par diverses méthodes chromatographiques et identifier les composés isolés par des analyses structurales et spectroscopiques.

Des travaux préliminaires ont été réalisés sur plusieurs extraits méthanoliques de plantes potentiellement anti-inflammatoires afin de sélectionner le plus actif. Les résultats obtenus ont démontré que le Solidago canadensis était l'espèce la plus active. Celle-ci a donc été étudiée dans le but d'identifier les composés actifs. Par la même occasion, les activités antioxydante et anticancéreuse de plusieurs extraits de plantes ont été évaluées dans le cadre de ce projet de maîtrise. 


\subsection{Structure du mémoire}

Ce mémoire est divisé en huit chapitres. Le premier chapitre présente la problématique ainsi que les objectifs du projet de recherche. Le chapitre II est une revue de littérature scientifique à propos de la botanique, des usages, de la phytochimie et de la pharmacologie du Solidago canadensis. Le chapitre III rapporte l'évaluation de l'activité anticancéreuse de composés isolés à partir des fleurs de Solidago canadensis et l'isolation d'un nouveau diterpène de la famille des labdanes. Ces travaux ont été publiés dans Chemical and Pharmaceutical Bulletin (Bradette-Hébert, M.E., Legault, J., Lavoie, S., Pichette, A., 2008. A new labdane diterpene from the flowers of Solidago canadensis. Chemical and Pharmaceutical Bulletin 56, 82-84). Le chapitre IV présente les résultats sur l'activité antioxydante et anti-inflammatoire des extraits méthanoliques de fleurs, de feuilles et de tiges de Solidago canadensis. Les chapitres V à VIII rapportent respectivement l'état d'avancement du projet, les conclusions et perspectives, la bibliographie et les annexes. 


\section{CHAPITRE II}

REVUE DE LITTÉRATURE : Solidago canadensis Linné 


\section{Revue de littérature : Solidago canadensis Linné}

\subsection{Botanique}

Le genre Solidago comprend environ 125 espèces presque toutes nord-américaines et fait partie de la famille des Astéracées. Le Solidago canadensis, aussi connu sous le nom de verge d'or du Canada, est une plante herbacée vivace indigène du Canada (Figure 1) (Marie-Victorin, 1995).

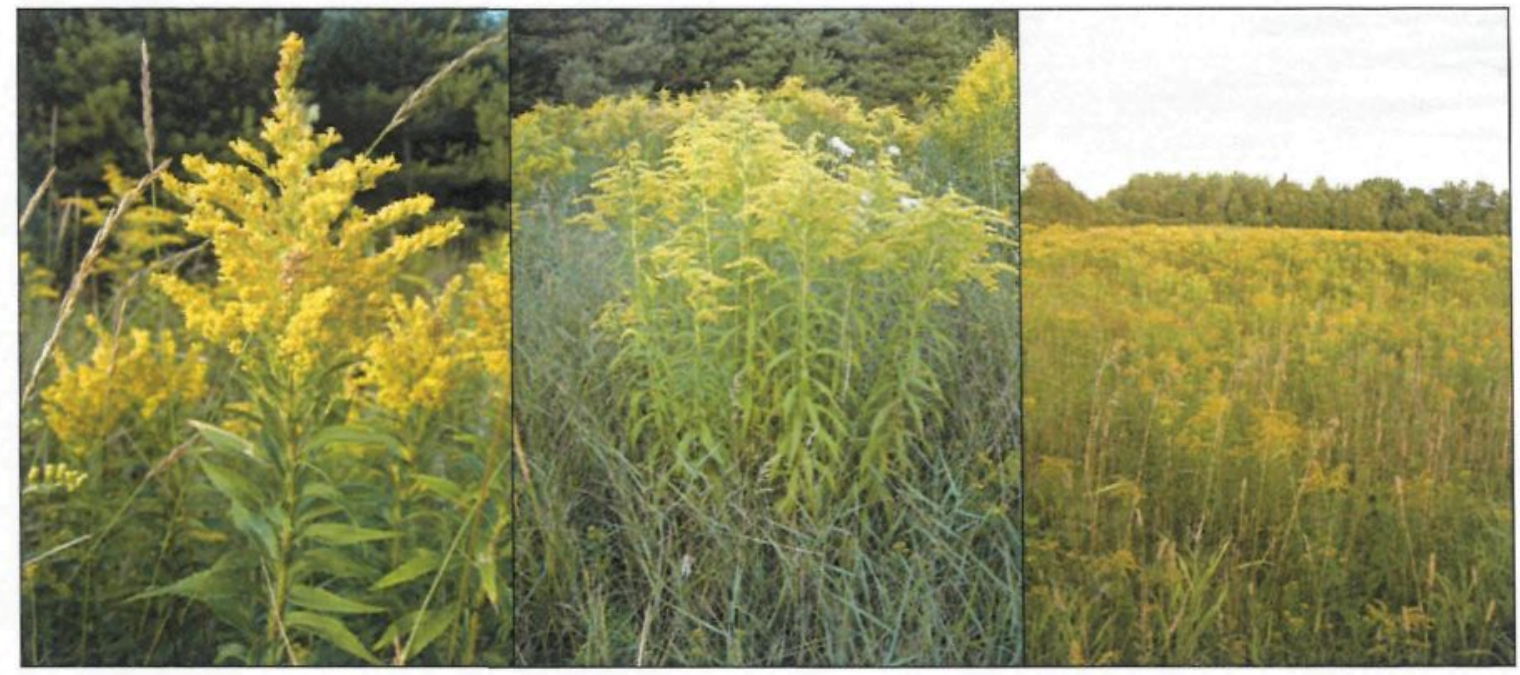

Figure 1. Solidago canadensis L. 
Le Solidago canadensis L. est pour ainsi dire présent partout en Amérique du Nord et il est naturalisé en Europe (Boufford, 1993).

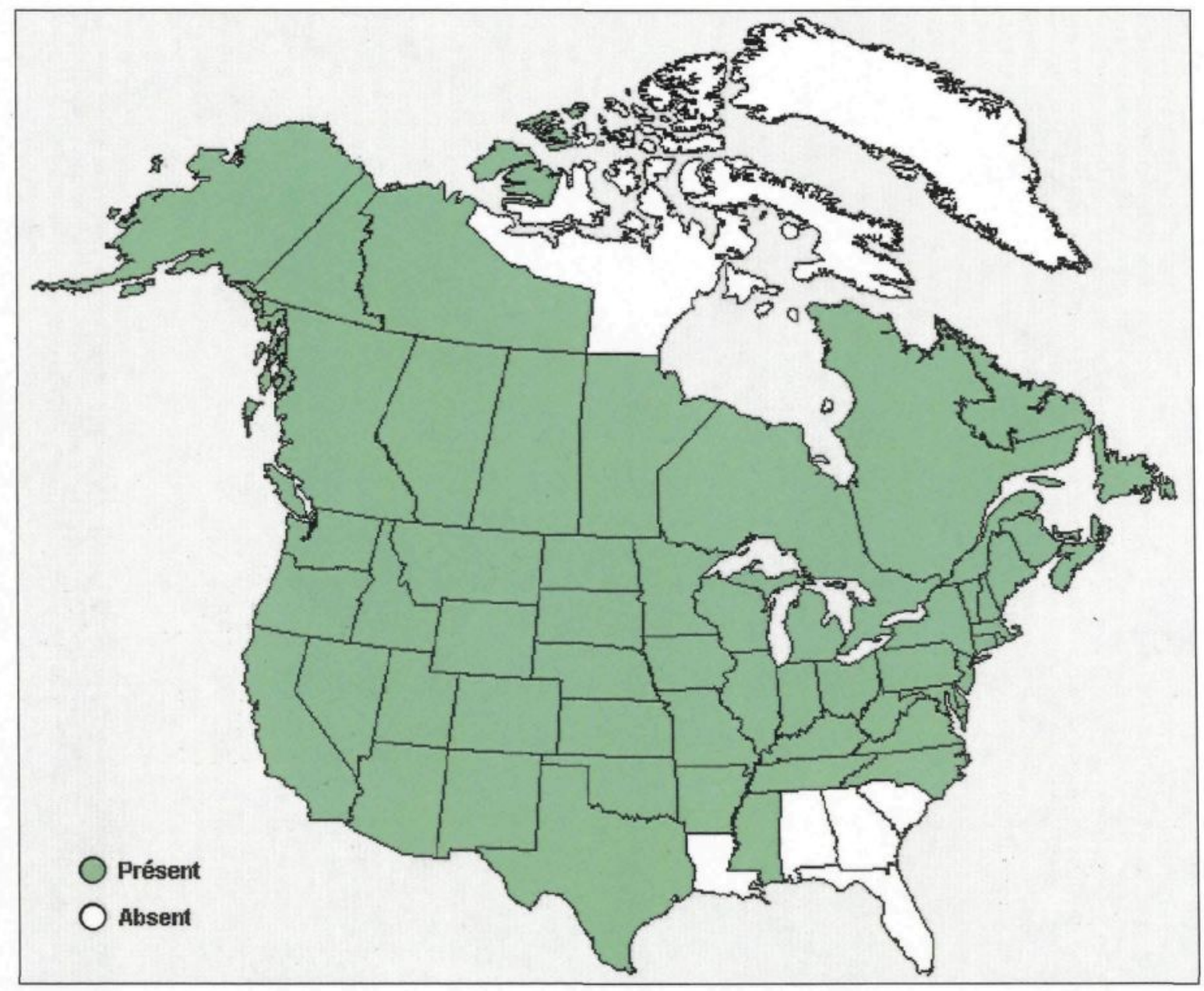

Source : http://plants.usda.gov/java/profile?symbol=SOCA6: Natural resources conservation service, United States department of agriculture. Dernière mise à jour : 27-03-2007

Figure 2. Distribution du Solidago canadensis L. en Amérique du Nord 
La verge d'or du Canada possède une tige grêle d'environ 30 à $150 \mathrm{~cm}$ de hauteur. Ses feuilles sont minces, alternées, linéaires, pointues et trinervées. Ses capitules d'une couleur jaune sont très petits ( 2 à $2.8 \mathrm{~mm}$ de hauteur) et nombreux. L'inflorescence apparaît en panicule pyramidale et les capitules sont unilatéralement disposés sur les branches de la grappe. Cette espèce amorce sa floraison en période estivale et celle-ci persiste jusqu'à l'automne (Marie-Victorin, 1995). La verge d'or du Canada forme des colonies très denses qui sont favorisées par une reproduction par graines et par rhizomes qui leur assurent une expansion prolifique. Cette espèce s'acclimate facilement à des sols de types variés et on la retrouve dans des écosystèmes différents. Elle est d'ailleurs considérée comme une plante envahissante dans les zones humides, les lieux incultes, les clairières et les prairies humides. Elle fait concurrence aux autres espèces en couvrant le sol et en étouffant la végétation environnante (Weber, 1998). 


\subsection{Usages}

Le Solidago canadensis est reconnu pour ses usages en médecine traditionnelle amérindienne (Tableau 1). D'ailleurs, l'utilisation de cette plante pour des applications liées à la douleur et l'inflammation est rapportée pour différents peuples ancestraụx.

Tableau 1. Usages ethnopharmacologiques du Solidago canadensis en Amérique du Nord

\begin{tabular}{|c|c|c|c|}
\hline Traitement & $\begin{array}{c}\text { Partie de la } \\
\text { plante }\end{array}$ & Forme & Peuple ancestral \\
\hline Analgésique & Fleurs et racines & Infusion & Iroquois \\
\hline Morsures de serpent & Racines & Mastication & Iroquois \\
\hline Brûlures & Fleurs & Compresse humide & Ojibwa (Chippewa) \\
\hline Ulcères & Fleurs & Compresse humide & Ojibwa (Chippewa) \\
\hline Analgésique & Fleurs & Infusion & Zuni \\
\hline Troubles gastro-intestinaux & Fleurs & Infusion & Iroquois \\
\hline Troubles du foie & Fleurs & Infusion & Iroquois \\
\hline Sédatif & Racines & Infusion & Iroquois \\
\hline Émétique & Fleurs et racines & Infusion & Iroquois \\
\hline Diarrhée & Fleurs & Infusion & Okanagan-colville \\
\hline Diarrhée & Fleurs et pousses & Décoction & Thompson \\
\hline Sédatif & Plante entière & Décoction & Thompson \\
\hline Fièvre & Non spécifié & Infusion & Algonquin \\
\hline
\end{tabular}

Source : Moerman, D.E., "Native American ethnobotany", Third edition, Ed. Timber Press Inc., Portland, United States, 2000, pp. 536. 


\subsection{Phytochimie}

Plusieurs espèces issues du genre Solidago comme le Solidago virgaurea, le Solidago gigantea et le Solidago graminifolia sont reconnues pour leur contenu fortement élevé en métabolites secondaires variés. En effet, différents composés phénoliques, plusieurs flavonoïdes, polysaccharides, diterpènes, triterpènes, saponosides, tannins et composés volatils ont été rapportés pour ce genre (Kalemba, 1994; Thiem et al., 2001).

D'abord, une étude exhaustive de l'huile essentielle de Solidago canadensis a mené à l'identification de 51 composés volatils. Ces travaux montrent que l'huile essentielle est principalement composée d' $\alpha$-pinène (1), de germacrène $D(2)$ et de limonène $(3)$ avec des concentrations relatives de $59.5 \%, 15.2 \%$ et $9.7 \%$ (Kalemba et Thiem, 2004).

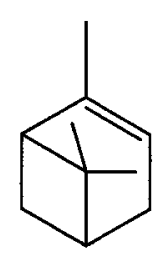

1

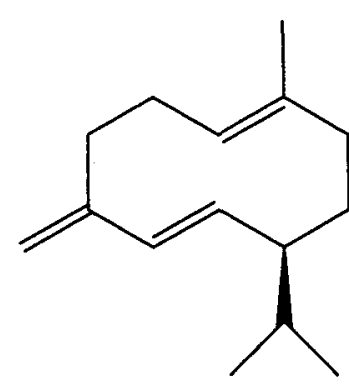

2

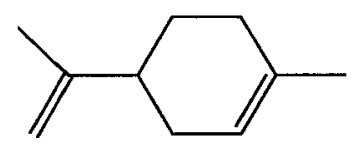

3

Figure 3. Structures des principaux constituants de l'huile essentielle de Solidago canadensis. 
D’autre part, plusieurs composés phénoliques ont également été identifiés dans la verge d'or du Canada. Des travaux ont mené à l'isolation de plusieurs acides phénoliques incluant les acides caféique (4), salicylique (5), p-hydroxybenzoïque, vanillique (6), protocatechuique (7), syringique (8), ferulique (9), p-coumarique (10), sinapique (11), chlorogénique (12), néochlorogénique (13), 3,5-di- $O$-caffeoylquinique (14), 4,5-di- $O$ caffeoylquinique (15) et un dérivé de l'acide dattelique (Kalemba, 1992; Pauli et al., 1998; Thiem et al., 2001; Apáti et al., 2002; Apáti et al., 2003; Papp et al., 2004).<smiles>O=C(O)C=Cc1ccc(O)c(O)c1</smiles>

4<smiles>COc1cc(C(=O)O)cc(OC)c1O</smiles>

8<smiles>O=C(O)c1ccccc1O</smiles>

5<smiles>COc1cc(/C=C/C(=O)O)ccc1O</smiles>

9<smiles>COc1cc(C(=O)O)ccc1O</smiles>

6<smiles>O=C(O)/C=C/c1ccc(O)cc1</smiles>

10<smiles>O=C(O)c1ccc(O)c(O)c1</smiles>

7<smiles>COc1cc(/C=C/C(=O)O)cc(OC)c1O</smiles>

11<smiles>CC(=O)/C=C/c1ccc(O)c(O)c1</smiles>

$$
\begin{array}{ll}
12 & R^{1}=R^{2}=H, R^{3}=\text { caffeoyl } \\
13 & R^{1}=\text { caffeoyl, } R^{2}=R^{3}=H \\
14 & R^{1}=H, R^{2}=R^{3}=\text { caffeoyl } \\
15 & R^{1}=R^{2}=\text { caffeoyl, } R^{3}=H
\end{array}
$$

Figure 4. Structures d'acides phénoliques présents dans le Solidago canadensis. 
Plusieurs flavonoïdes ont été rapportés dans des extraits de Solidago canadensis incluant: la nicotiflorine (16), la rutine, l'hyperoside, l'isoquercitrin, le quercitrin, l'afzeline (17), la quercétine (18), la quercétine-3-(6"-O-acetyl)- $\beta$-glucopyranoside, le kaempférol (19), l'astragaline, le kaempférol-3-(6"-O-acetyl)- $\beta$-glucopyranoside, l'isorhamnétine (20), l'isorhamnétin-3-(6"-O-acetyl)- $\beta$-glucopyranoside et le narcissin (Krepinsky et Herout, 1962; Apáti et al., 2002; Apáti et al., 2003; Papp et al., 2004).<smiles>C[C@H]1O[C@H](CC[C@H]2O[C@H](Oc3c(-c4ccc(O)cc4)oc4cc(O)cc(O)c4c3=O)[C@@H](O)[C@H](O)[C@H]2O)[C@H](O)[C@@H](O)[C@H]1O</smiles>

16<smiles>C[C@H]1O[C@H](Oc2c(-c3ccc(O)cc3)oc3cc(O)cc(O)c3c2=O)[C@H](O)[C@@H](O)[C@H]1O</smiles>

17<smiles>O=c1c(O)c(-c2ccc(O)cc2)oc2cc(O)cc(O)c12</smiles>

19<smiles>O=c1c(O)c(-c2ccc(O)c(O)c2)oc2cc(O)cc(O)c12</smiles>

18<smiles>COc1cc(-c2oc3cc(O)cc(O)c3c(=O)c2O)ccc1O</smiles>

20

Figure 5. Structures de flavonoïdes provenant du Solidago canadensis. 
Des études portant sur des extraits de Solidago canadensis ont également mené à l'isolation du diterpène 21. De plus, la présence des labdanes 22-24 a été rapportée (Anthonsen et al., 1969; Bohlmann et al., 1980). La solidagénone (25) est le diterpène majoritaire de la verge d'or du Canada (Anthonsen et al., 1969; Anthonsen et al., 1970). Les diterpènes de type clérodane 26-32, dont l'acide kolavénique (26), ont aussi été identifiés (Lu et al., 1993) et quelques triterpènes de type lupane ont été isolés: le 3ß-(3Racétoxyhexadécanoyloxy)-lup-20(29)-ène (33), le 3ß-(3-kétohexadécanoyloxy)-lup-20(29)-

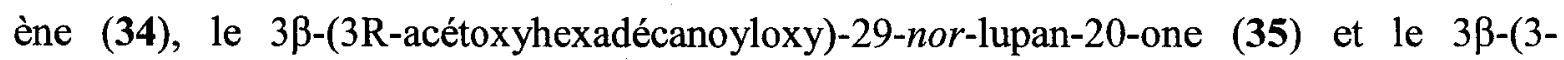
kétohexadécanoyloxy)-29-nor-lupan-20-one (36) (Chaturvedula et al., 2004).

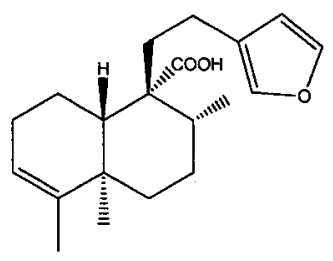

21

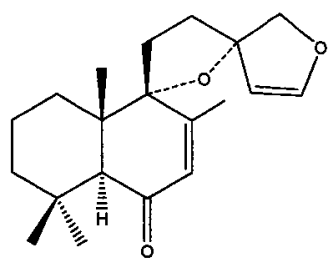

24

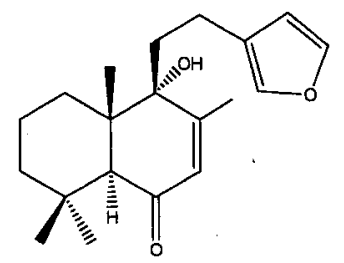

22

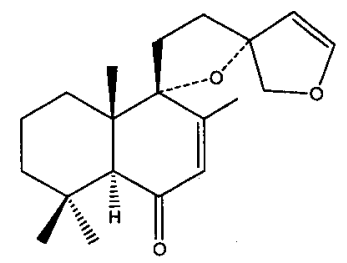

23

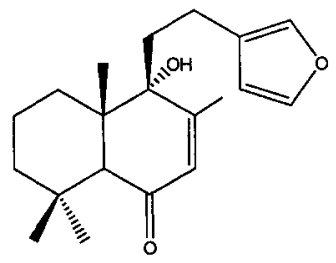

25

Figure 6. Structures de diterpènes retrouvés dans le Solidago canadensis. 


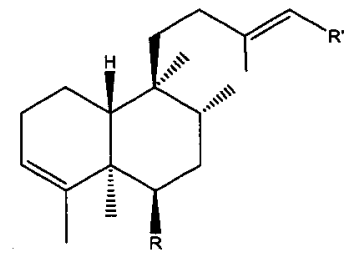

$$
\begin{array}{ll}
\mathbf{2 6} & \mathrm{R}=\mathrm{H}, \mathrm{R}^{\prime}=\mathrm{COOH} \\
\mathbf{2 7} & \mathrm{R}=\mathrm{H}, \mathrm{R}^{\prime}=\mathrm{CH}_{2} \mathrm{OH} \\
\mathbf{2 8} & \mathrm{R}=\mathrm{OAngelate}, \mathrm{R}^{\prime}=\mathrm{COOH} \\
\mathbf{2 9} & \mathrm{R}=\text { OTiglate, } \mathrm{R}^{\prime}=\mathrm{COOH}
\end{array}
$$

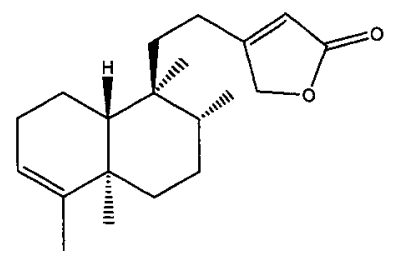

30

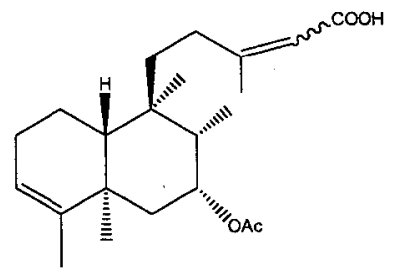

31 13E

$3213 Z$

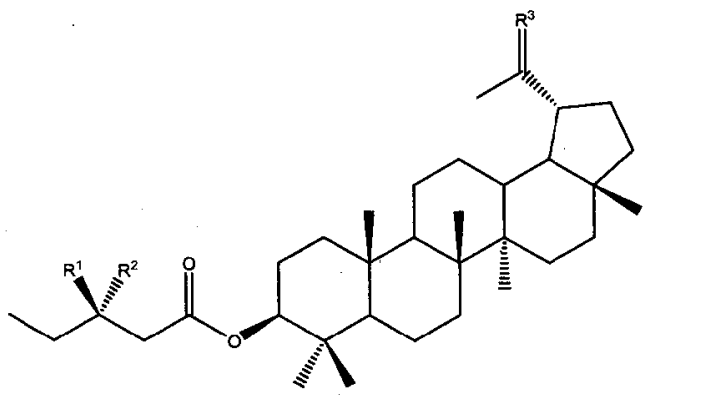

$$
\begin{array}{ll}
33 & \mathrm{R}^{1}=\mathrm{OCOCH}_{3}, \mathrm{R}^{2}=\mathrm{H}, \mathrm{R}^{3}=\mathrm{CH}_{2} \\
\mathbf{3 4} & \mathrm{R}^{1}=\mathrm{R}^{2}=\mathrm{O}, \mathrm{R}^{3}=\mathrm{CH}_{2} \\
\mathbf{3 5} & \mathrm{R}^{1}=\mathrm{OCOCH}_{3}, \mathrm{R}^{2}=\mathrm{H}, \mathrm{R}^{3}=\mathrm{O} \\
\mathbf{3 6} & \mathrm{R}^{1}=\mathrm{R}^{2}=\mathrm{R}^{3}=\mathrm{O}
\end{array}
$$

Figure 7. Structures de diterpènes de type clérodane et de triterpènes de type lupane issus du Solidago canadensis. 
Par ailleurs, des travaux portant sur le Solidago canadensis ont conduit à la découverte de saponines de type bisdesmosidique (Reznieck et al., 1990; Reznieck et al., 1991; Reznieck et al., 1992). La génine (37) de ces saponines est illustrée à la figure 7.

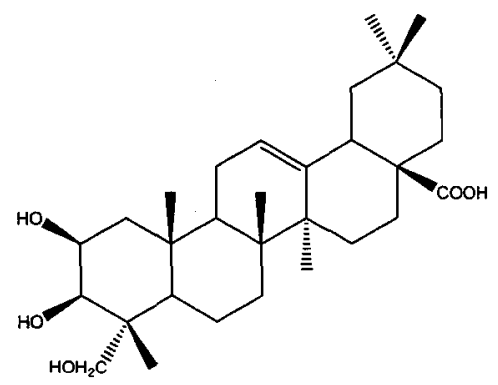

37

Figure 8. Structure de la génine des saponines isolées à partir du Solidago canadensis.

D'autres travaux de recherche portant sur le Solidago canadensis ont mené à l'isolation des esters de type matricaria 38-41 ( $\mathrm{Lu}$ et al., 1998), des sesquiterpènes 42 et 43 et de l'époxyde de caryophyllène 44 (Bohlmann et al., 1980).

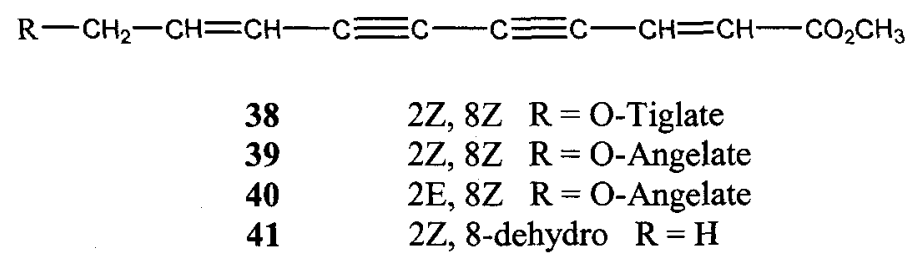

Figure 9. Structures des esters retrouvés dans le Solidago canadensis.<smiles>C=C1/C=C/C(C(C)C)CCC2=CCCC(=C)/C2=C\1</smiles>

42<smiles>CC1=CCCC=C2CCC(CC2)C1C(C)(C)C</smiles>

43

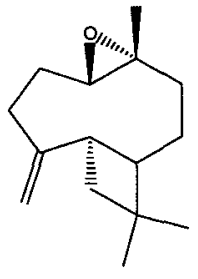

44

Figure 10. Structures des sesquiterpènes et de l'époxyde de caryophyllène provenant du Solidago canadensis. 
Finalement, une étude a mené à l'isolation du lupéol (45), de l'acétate de lupeyle, de l'acide ursolique (46), du cycloarténol (47), du palmitate cycloartényl, de l'acétate d' $\alpha$ amyrine et du stigmastérol (48) (Chaturvedula et al., 2004).

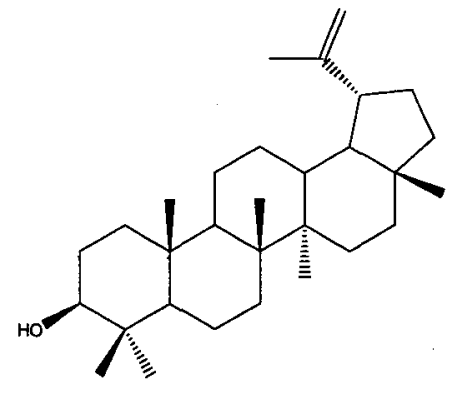

45

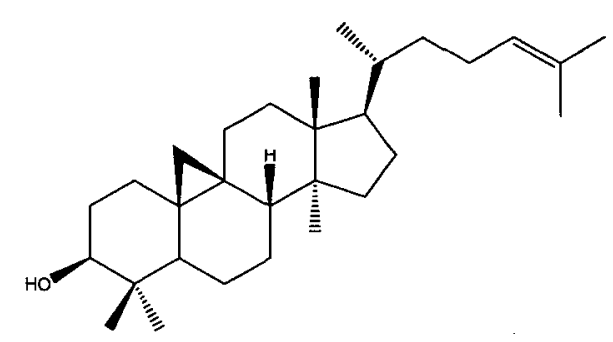

47

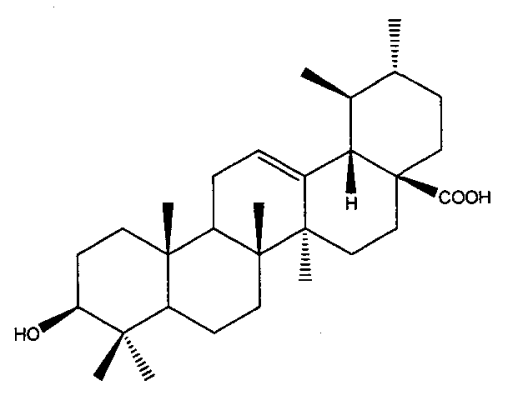

46

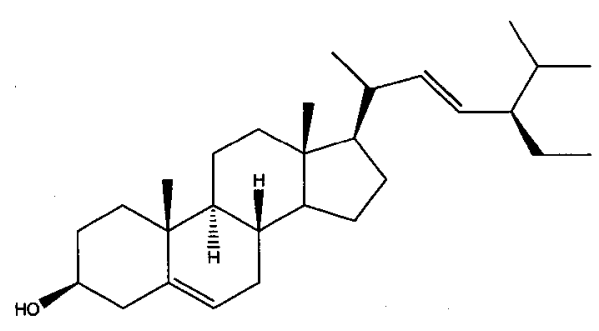

48

Figure 11. Structures de composés terpéniques isolés dans le Solidago canadensis. 


\subsection{Pharmacologie}

Plusieurs activités au niveau biologique ont été rapportées dans la littérature pour le genre Solidago. Entre autres, les activités analgésique, anti-inflammatoire, antiphlogistique, antinéoplasique, immunobiologique et urologique pour le Solidago virgaurea (Metzner et al., 1984; Arens-Corell and Okpanyi, 1990; Gross et al., 2002; Melzig, 2004; Choi et al., 2005). Par ailleurs, des activités au niveau anti-inflammatoire, diurétique et spasmolytique ont été rapportées pour le Solidago gigantea (Leuschner, 1995).

En ce qui concerne le Solidago canadensis, certains polyacétylènes provenant des fleurs ont inhibé la croissance de Mycobacterium tuberculosis et de Mycobacterium avium (Lu et al., 1998). Un effet protecteur du système gastrique a été observé pour la solidagénone isolée à partir de rhizomes de Solidago canadensis (Schmeda-Hirschmann et al., 2002). Plusieurs composés provenant des tiges et des racines dont des triterpènes de la famille des lupanes ont inhibé l'activité lyase de l'ADN polymerase $\beta$ (Chaturvedula et al., 2004). Enfin, le potentiel antioxydant est l'activité biologique ayant suscité le plus d'intérêt chez le Solidago canadensis. En effet, il a été démontré que des extraits de la plante entière possèdent une activité anti-radicalaire et antioxydante (Apáti et al., 2003; Papp et al., 2004). De plus, un extrait de racines a montré un pouvoir anti-radicalaire (McCune and Johns, 2002). 


\section{CHAPITRE III}

A New Labdane Diterpene from the Flowers of Solidago canadensis

Article publié dans Chemical and Pharmaceutical Bulletin, 56 (1), 82-84, 2008. 


\section{Résumé}

Le Solidago canadensis L. est une plante herbacée de la famille des Astéracées. En Amérique du Nord, les fleurs de cette plante étaient fréquemment utilisées en médecine traditionnelle amérindienne. Dans le but de valoriser la biomasse de la forêt boréale par l'étude de l'activité biologique de composés d'origine naturelle, un extrait de fleurs de Solidago canadensis a été étudié. Un nouveau diterpène de type labdane, le $9 \alpha, 16 \xi$ dihydroxy-6-oxo-7,13-labdadièn-15,16-olide (solicanolide, 1) et six composés connus : la quercétine (2), l'acide 3-O-caffeoylquinique (3, acide néochlorogénique), l'acide 5-Ocaffeoylquinique (4, acide chlorogénique), l'acide 4,5-di- $O$-caffeoylquinique (5), l'acide 3,5-di-O-caffeoylquinique (6) et l'acide 3,4-di-O-caffeoylquinique (7) ont été isolés. Le composé 7 (acide 3,4-di-O-caffeoylquinique) est rapporté pour la première fois à partir du Solidago canadensis. Cet article décrit l'isolation des composés 1-7 et l'élucidation de la structure du nouveau composé (1). L'évaluation de l'activité anticancéreuse de tous les composés isolés est décrite. Parmi tous les composés isolés, seul le composé 1 possède une activité cytotoxique. 


\title{
A New Labdane Diterpene from the Flowers of Solidago canadensis
}

\author{
Marie-Eve Bradette-Hébert, Jean Legaul, Serge Lavole, and André Pichette* \\ LASEYE, Departement des Sciences Fondamentales, Unthersité di Owebes à Chicoutimi; 555 Boul. Université, \\ Chicoutimi, Québec. G7H 2B1, Canada. Received June 28, 2007; accepted September 25, 2007
}

A new labdane diterpene, $9 \alpha, 16 \xi$-dihydroxy-6-0x0-7,13-labdadien-15,16-0lide (solicanolide, 1) and six known compounds jentited as quercetin $(2), 3-O$-caffeoviquinic acid (3, neochlorogenic acid), 5-O-caffeylquinic acid (4, chlorogenic acid), 4,5-di-O-caftenlquinic acid (5), 3,5-di-O-caffeoylquinic acid (6) and 3,4-diO-caffeoylquinic acid (7) were isolated from the flowers of Solidago cantalensis. To our knowledtre, compound 7 was isolated for the first time in $S$. canalensis. This work describes the isolation of componnds $1-7$ and the structure elucidation of a new compound identified as compound 1 . Solicanolide (1) showed cytotoxic activity

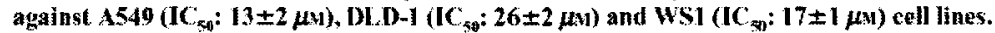

Koy words Soldiazo canedersis: isolation; labdane; solicanolide; cytotonicity; caffeoylquinic acid

Soldogro cancadensis $\mathrm{L}$. is an Asteraceac widely distributed across North America, occurring in almost every state of the U.S.A. and throughout Canada. Numerous interesting secondary metabolites such as: flavonoids, phenolic acids and glucosides, polysaccharides, diterpenes, triterpenoid saponosides, tannins and essential oils" were reported for the genus Solidago. Previous phytochemical studies of $S$. cantadensi have led to the isolation of flayonoils, ${ }^{2.37}$ phenolic acids, ${ }^{4}$ sesquiterpenes, ${ }^{5)}$ diterpenes ${ }^{s, 7}$ and saponins. The flowers of S. canuderus were used in traditional Amerindian madicine as an analgesic." burns and ulcers treatment, ${ }^{19}$ febrifuge, ${ }^{10}$ gastrointestinal ${ }^{1,12}$ and liver ${ }^{11}$ aids, In spite of the wide. spread use of $S$. canalensis, few investigations were carried oul on its bioactive secondary metabolites.

Fractionation of the flower extracts of Solidago canadensis resulted in the isolation of a now diterpene, $9 \alpha, 16 \xi$-dihydroxy-6-0xo-7,13-labdadien-15,16-olide (solicanolide, 1 and six known compounds identified as quercetin (2), 3 O-caffeoylquinic acid (neochlorogenic acid) (3), 5-O-caf feoylquinic acid (chlorogenic acid) (4), 4,5-di-O-catfeoylquinic acio (5), 3.5-di $O$-caffeoylquinic acid $(6)$ and 3.4-diO-caffeoylquinic acid (7). To our knowledge, compound 7 Was isolated for the first time in $S$. canadensis. This work describes the isolation of compounds $1-7$ and the structure elucidation of a new compound jdentified as compound 1 . The cytotoxicity of solicanolide 1 ) was also investigated in this paper.

\footnotetext{
Experimental

Ceneral Expertmental Procedures NMR spectra were recorded in methanolod $d_{4}$ on a Bruker Avance 400 spectrometer $(5 \mathrm{~mm} \mathrm{QNP}$ with Z-gradient prowa) operating at $400.13 \mathrm{MHz}\left({ }^{1} \mathrm{H}\right)$ or $100.61 \mathrm{MHz}\left({ }^{13} \mathrm{C}\right)$. Chemical shifts were referenced relative to the corresponding residual solvent signals $\left(\delta_{\mathrm{TW}}, 3.3 / 49.0 \mathrm{pmm}\right.$, respectivaly). The accurate mass determination was carried out with an Applied Biosystems QSTAR XL Hybrid LCMSMS system. Optical totation was obtained on a Jace DIP-360 digital polarineter. Analytical HPLC-DAD-MS analusis were performed on an Agilent 1100 serjes HPLC-DADMS system. A Zarbax ODS C18 column $(5 \mu \mathrm{m}$, $150 \times 4.6 \mathrm{~mm}$ ) maintained at $25^{\circ} \mathrm{C}$ was utilised. The flow rate was $1 \mathrm{~m} / \mathrm{min}$. Agilent G1315B diode array detector was used for UV deterion. The UV spectra were recorted from 190 to $400 \mathrm{~mm}$. An Agilent mass selective detector (VL modell equipred with an aimosnheric chemical ionisation source (APCI) was employed for MS detection. All mass spectra were acguired in the nezative ion mode. The full scan mass spectrum was recorded over the range of $m / z 100-1000$. Temperature of the drying gas $\left(\mathrm{N}_{3}\right)$ was $350^{\circ} \mathrm{C}$ with a gas flow rate of $101 \mathrm{~min}$ and a nebulizing pressure of $40 \mathrm{psi}$. The imtisation vollage was $4000 \mathrm{~V}$ and the corona current was $15 \mathrm{~mA}$. Al F.PLC.
}

separalions were perfonned on a preparative Agilent 1100 series (Agilem

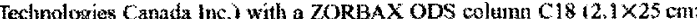
$7 \mu \mathrm{m})$ at a flow rate of $16 \mathrm{ml}$ imin. Compounds were detected by UV absorption at $254 \mathrm{~mm}$. For all HPLC procedures, solvent $A$ was $\mathrm{H}_{2} \mathrm{O}+0.1 \%$ $\mathrm{HCOOH}$, solven B was $\mathrm{MeOH}+9.1 \% \mathrm{HCOOH}$ and solvent $\mathrm{C}$ was

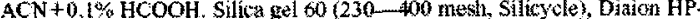
30) (Supelco) and Cl8 silica gel (230 - $400 \mathrm{mesh}$, EMD) were used for $\mathrm{col}$ unn chromatography. The solvents were purchased from EMD. Thin-layer chrornatography (TLC) was performed on silica gel $60 F_{24}$ aluminiun sheets (Sificycle) using EtOA-MeOH $-\mathrm{H}_{3} \mathrm{O}(100: 16.5: 13.5)$ or $\mathrm{CHCl}_{3}$ $\mathrm{MeOH}(10: 1)$ as solvent systerns. Detection of the phenolic compounds was cartied out by spraving natual products with NPPEG reagent $11 \%$

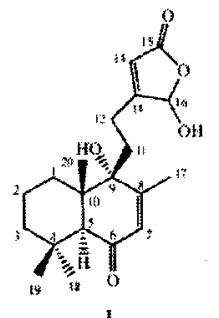<smiles>O=c1c(O)c(-c2ccc(O)c(O)c2)oc2cc(O)cc(O)c12</smiles><smiles>CC(=O)/C=C/c1ccc(O)c(O)c1</smiles>

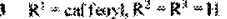

$$
\begin{aligned}
& 4 \quad R^{2}:=R^{2}: \cdots: R^{3}=\text { weffoct }
\end{aligned}
$$

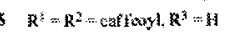

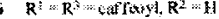

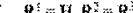

Fig. 1. Strutures of Compounds 1 ....?

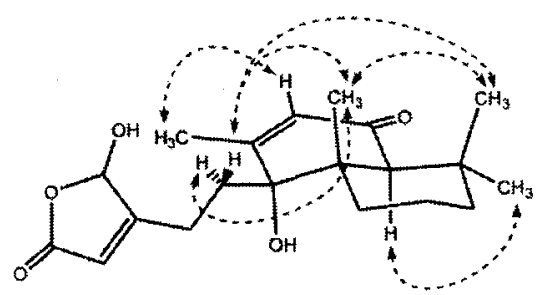

Fig. 2, ${ }^{1} \mathrm{H}-{ }^{1} \mathrm{H}$ NOESY Correlations of Compound 
diphonylboric acid 2-aminoethylester in methanol and $5 \%$ prolyothylene glycol in ethanol) and obserwing ander UN fight before and after revelation (254, $365 \mathrm{~nm}$ ). Quetcetin and thlorogenic acid standards are from SigmaAldrick.

Plant Material The tlowers of siblidago canademsis $L$. were collected in September 2004 in St-Folicien $\left(48^{\circ} 40^{\prime} \mathrm{N}, 72^{\circ} 27^{\prime} \mathrm{W}\right)$, Quebec, Canatin. The specimens were identified by Mr. Patrick Nadeau (Département des Science Fondamentales, Eniversité du Québec à Chicoutimí, Ouébec, Canada). A vacher specimen was deposited in the Lotis-Maric Herbarium of Universilé Laval, Québec, Canada (QFA-492115).

Extraction and Istlation The air-stied flowers of Solikaze canudensis $(285 \mathrm{~g})$ were extracted with hot methanol $(3 \times 2.51)$ and then with hot methand $80 \%(3 \times 2.51)$ for $2 \mathrm{~h}$. The combined extracts were eyaporated under a redteed pressure, yielding a residne $(103.81 \mathrm{~g})$, which was siespended in water $(400 \mathrm{~m})$ ) and successively extracted with dichloromethane $(3 \times 200 \mathrm{ml})$ and ethyl nectate $(6 \times 400 \mathrm{ml})$, yielditug dichloromethane, ethyl acetake and aque ons fractions.

The ethyl acetate fraction ( $15.6 \mathrm{~g}$ ) was separated into wo fractions $(A, B)$ by chromatograply over Dition $(3,2 \times 40.5 \mathrm{~cm})$ eluting with $\mathrm{MeOH}-\mathrm{H}, \mathrm{O}$ (from 50 to $100 \%$. Fraction $8(3.0 \mathrm{~g}$ ) was shromatographed on a silica gel colum $(3.6 \times 120.0 \mathrm{~cm})$ with $\mathrm{CHCh}_{3} \mathrm{MeOH}(10 ; 1)$ to obtain six fractions (BI-136). From $\mathrm{B} 1(91.4 \mathrm{mg})$, compound 1 (S.4 $\mathrm{mg}$ ) was purifed by prephrative HPLC ( $40 \%$ solvent $A, 60 \%$ solvent B). Fractions B5 and B6 were combined and then fractionated on a silica gel column $(3.0 \times 45.0 \mathrm{~cm})$ with $\mathrm{CHCl}, \mathrm{MeOH}(10: 1)$ to give compound $2(53.6 \mathrm{mg})$

The aqueous fraction $(66.13 \mathrm{~g})$ was separated into three fractions $(C, D, B)$ by chromatography on a silica gel colum $(7.0 \times 60.0 \mathrm{~cm})$ using an isocratic solvent system of EAOAc-MeOH $\mathrm{H}_{2} \mathrm{O}(100: 16.5: 13.5)$. Faction D (6. $70 \mathrm{~g}$, which contained the major constituents, was divifed into six fractions $f D 1-D 6)$ using Diaion $(3.2 \times 70.5 \mathrm{~cm})$ by elution with MeOH $20 \%$ Fraction D2 $(1.03 \mathrm{~g})$ was separated into nitte fractions (D2A - . D2I) by chro matography on a $\mathrm{C} 18$ silica gel column $(1.6 \times 46,0 \mathrm{~cm})$ and eluted with MeOH $10 \%$. From D2A $(214.2 \mathrm{mg})$, compounds $3(3.8 \mathrm{ng})$ and $4(9.3 \mathrm{mg})$ were purified by preparative HPLC (94\% solvent $A, 6 \%$ solven C). Fractions D2E $(135.1 \mathrm{mg})$ and $\mathrm{D} 2 \mathrm{~F}(64.9 \mathrm{mg})$ were combined and then, fractionated by preparative HPLC ( $84 \%$ solvent A, $16 \%$ solvent $C$ ) to yield compounds $5(9.1 \mathrm{mg}), 6$ (7.0) $\mathrm{mg})$ and $7(11.4 \mathrm{mg})$

Solicanolide $(1)$ : Yellow oil: $\left.[\alpha]_{1}^{35}-30.\right]^{\circ}(c=0.1$. MeOH $)$, LV $\lambda_{\text {max }}$ (MeOH) $216 \mathrm{~nm}$; HR-ESI-MS m/z $371.1834 \quad[\mathrm{M}+\mathrm{Na}]^{+}$(Calcd for $\left.\mathrm{C}_{30} \mathrm{H}_{38} \mathrm{O}_{5} \mathrm{Na}, 371.1842\right):{ }^{1} \mathrm{H}$ - and ${ }^{17} \mathrm{C}-\mathrm{NMR}$ : see Table 1 .

Cell Colture The human lung carcinoma A549 (itCCL-1 85), colotewal adenocarcinoma DLD 1 ( $+\mathrm{CCl}-22)$ ) and skin fibroblast WS1 (\#CRL-1502) cell línes were all obtained from the American Type Culture Collection (ATCC. Manassas, U.S.A.) Cells fines were grown in mintmin essential meztim containing Earles salts (Mediatech Cellgro", Hendon, U.S.A.), supplemented with $10 \%$ fetal calf serum (Hyclone, Logan, US.A.) I X tion of vitamins, $1 \times$ sodium prnyate, $i \times$ non-essential amino acids, $100 \mathrm{~J}$ of penicilin and $100 \mathrm{Hg} / \mathrm{ml}$ of streptonvin (Medistech Celfgrow, Cells were cultured at $37^{\circ} \mathrm{C}$ in a hamidified atmosphere containing $5 \% \% \mathrm{CO}$

Cytotoxic Assay Exponentially growing cells were plated at a density of $5 \times 10^{3}$ cells per well in 96-well microplates (BD Falcon) in $100 \mu$ l of culture mediun and were allowed to allere for $16 \mathrm{~h}$ before treatment. The cells were then incubated for $48 \mathrm{~h}$ in the presence or absence of $100 \mu \mathrm{l}$ of increasing concentrations of compounds $1-7$ dissolved in culture medium and an appropriate solvent. The final concentration of solvent in the culture nedium was maintained at $0.25 \%$ (viv) to awoid toxicity. Cytotoxicity was assessed using the resazurin reduction test ${ }^{\mathrm{t} \text {. }}$ Fluorescence was measured on an automated 96-well Fluoruskan Ascent $\mathrm{F}^{\mathrm{T}}{ }^{\mathrm{Th}}$ plate rewder (Labsystems) using an excitation wavelength of $530 \mathrm{~mm}$ and an emission wavelength of $590 \mathrm{~mm}, \mathrm{Cy}$ totoxicity was expressed as the concentration of drug inbibiting cell growth by $50 \%\left(\mathrm{CC}_{30}\right)$

\section{Results and Discussion}

Compound 1 was obtained as an optical active yellow oil $\left([\alpha]_{D}^{25}-30.1^{\circ}\right.$. The molecular formula of compound 1 was established as $\mathrm{C}_{20} \mathrm{H}_{28} \mathrm{O}_{5}$ on the basis of HR-ESI-MS (Found at $m / z \quad 371.1834[\mathrm{M}+\mathrm{Na}]^{+}$. Calcd for $\mathrm{C}_{20} \mathrm{H}_{28} \mathrm{O}_{5} \mathrm{Na}$, 371.1842 ), ${ }^{1} \mathrm{H} .{ }^{13} \mathrm{C} . \mathrm{NMR}$ and DEPT spectra revealed four methyls, five nethylenes, four methines including two olefinics and seven quaternary carbons including a carbonyl and a quaternary alcohol (Table 1). The NMR spectra sug-
Table 1. NMR Assignments of Compound 1

\begin{tabular}{|c|c|c|c|c|c|}
\hline Pasition & ${ }^{3} \mathrm{C}^{-j}$ & Conneted $H^{3 / 3}$ & $\begin{array}{c}H \cdots H \\
\cos y^{*}\end{array}$ & HMBC" & NOESY \\
\hline 1 & $32.6[1]$ & $1.92(\mathrm{~m}) .1 .57(\mathrm{~m})$ & & H5, 21\} & \\
\hline 2 & $19.0(t)$ & $1.66(\mathrm{~m}), 1.53(\mathrm{mi})$ & $\mathrm{H}$ & & \\
\hline 3 & $43.9(t)$ & $1.35(\mathrm{~m}), 1.19(\mathrm{~m})$ & 102 & HII $\$, 19$ & \\
\hline 4 & $33.3(s)$ & $\ldots . .$. & & H5 18,19 & \\
\hline 5 & $56.8(d)$ & $288(s)$ & 120 & H18, 19,26 & Hifs \\
\hline 6) & $202,9(s)$ & .... & & 45 & \\
\hline 7 & $129.6(\mathrm{~d})$ & $5.66\{5\}$ & 117 & H17 & H17 \\
\hline 8 & $150.1(\mathrm{~s})$ & ....... & & HI? & \\
\hline 9 & $76,7(\mathrm{~s})$ & $\ldots . . . \cdot$ & & $45,7,17,20$ & \\
\hline 10 & $481(\$)$ & - & & $\mathrm{H} 5,20$ & \\
\hline 11 & $31.0(1)$ & $2.11(\mathrm{~m}) .194(\mathrm{~m})$ & & & H14.19.20 \\
\hline 12 & $25.4(1)$ & $2.65(\mathrm{n})$ & & & \\
\hline 13 & $1728(5)$ & $\ldots-.$. & & & 1114.18 \\
\hline 14 & $117.6(\mathrm{~d})$ & $5.45(s)$ & & H16 & $H 12.14$ \\
\hline 15 & $173.7(\mathrm{~s})$ & .......... & & 114,10 & \\
\hline 16 & (01) (d) & $610(s)$ & & $1: 14$ & $\mathrm{H} / 2$ \\
\hline 17 & $20.5(0)$ & $202(s)$ & $H ?$ & $\mathrm{H}$ ? & $H^{7}$ \\
\hline 18 & $34,3(q)$ & $1.14(\mathrm{~s})$ & & HIS & $\$ 15$ \\
\hline 19 & $22.2(q)$ & $1.18(5)$ & & $1 \mathrm{LS} S \mathrm{SB}$ & 1111,20 \\
\hline 20 & $18.8(4)$ & $1,02(s)$ & HS & HSS & H11. 19 \\
\hline
\end{tabular}

a) Mulniplictios were determined by DEPT. b) Connections wite deternined by gHSOC o Determined by aCOSY a) Correlation from $C$ to the indieated protons o) unambiquous NOESY cross peaks.

gests that compound 1 is a labdane diterpene. ${ }^{(\$, 15)}$

HMBC corralations between $\mathrm{H}-17\left(\delta_{4}, 2,02\right)$ and $\mathrm{C}-7 . \mathrm{C}-8$, $C-9\left(\delta_{c} 129.6,159.1,76.7\right.$ respectively) showed that the methyl group was branched $\beta$ on an $\alpha, \beta$-insaturated ketone and that the quaternary alcohol group was on $C .9$. The position of the ketone was further eonfirmed by the HMBC correlation between $\mathrm{H}-5\left(\delta_{11} 2.88\right)$ and $\mathrm{C}-6\left(\delta_{\mathrm{C}} 202.9\right)$. The sice chain was identified as a $\gamma$-hydroxy $\alpha, \beta$-unsaturated- $\gamma$. lactone by the presence of typical ${ }^{16)}{ }^{1} \mathrm{H}\left(\delta_{\mathrm{H}} 5.95,6.06\right)$ and ${ }^{1}$ C-NMR signals $\left(\delta_{\mathrm{C}}, 101.1,117.6,172.8,173.7\right)$

The relative stereochemistry of compound 1 was partially determined from the 2D NOESY spectrum. Cross-peaks between $\mathrm{H}-11\left(\delta_{\mathrm{H}} 1.94,2.11\right), \mathrm{H}-19\left(\delta_{\mathrm{H}} 1.18\right)$ and $\mathrm{H}-20\left(\delta_{\mathrm{H}}\right.$ $1.02)$ showed that all these groups are positioned on the same side. Unfortmately. NOESY cortelations between $\mathrm{H}-16\left(\delta_{\mathrm{H}}\right.$ $6.06)$ and both $\mathrm{H}-11\left(\delta_{\mathrm{H}}, 1.94,2.11\right)$ were observed with the same intensity which prevents the determination of the stereochemistry of the hydroxyl function at $\mathrm{C}-16$. However, while some authors observed both epimers at $\mathrm{H}-16$ of related compounds, ${ }^{1718}$ its single signal in the ${ }^{\prime} \mathrm{H}$ - and ${ }^{13} \mathrm{C}-\mathrm{NMR}$ spectra suggests that only one epimer was isolated.

The determination of the absolute stereochemistry by the Mosher ester method was precluded by the limited amount of this natural product. However, the chemotaxonomic information indicated that all labdanes from Solidago genus belong to the normal series ${ }^{5,1020}$ and by amalogy, compound 1 could be assigned to this series. Therefore, the strusture of compound 1 was istentified as $9 \alpha_{8} 16 \xi$-dihydroxy-6-0xo-7,13 labdadien-15,16-olide.

The other compounds isolated were identified as quercetin (2), 3-O-calfeoylquinic acid (3, neochlorogenic acid), 5-O caffeoylquinic acid (4, chlorogenic acid), 4.5-di-O-carfeoylquinic acid (5), 3,5-di- $O$-caffeoylquinic acid (6) and 3,4-di-O-caffeoylquinic acid (7). Identification of these compounds was established by NMR ( ${ }^{1} \mathrm{H},{ }^{13} \mathrm{C}$, DEPT, COSY, HSQC and HMBC) and HR-ESI-MS analyses. The data ob- 
Table 2. Cytotoxic Adtinty of lsolated Compounds against A549 Lung Carcinoma Cells, DLD 1 Colon Carcinoma Cells and Normal Fibroblasts. WS1

\begin{tabular}{cccc}
\hline \multirow{2}{*}{ Compound } & \multicolumn{3}{c}{ IC $_{5 \mathrm{k}}(\mu \mathrm{M})$} \\
\cline { 2 - 4 } & A549 & DLD-1 & WSI \\
\hline Etoposide & $1.1 \pm 0.1$ & $4.5 \pm 0.8$ & nd. \\
5-Fleorouracil & $4.8 \pm 0.6$ & $11 \pm 2$ & $n . d$ \\
1 & $13 \pm 2$ & $26 \pm 2$ & $17 \pm 1$ \\
2 & $>199$ & $>199$ & $>199$ \\
3 & $>57.5$ & $>57.5$ & $>57.5$ \\
4 & $>56$ & $>56$ & $>56$ \\
5 & $>109$ & $>109$ & $>109$ \\
6 & $>107$ & $>107$ & $>107$ \\
7 & $>36.8$ & $>36.8$ & $>36.8$ \\
\hline
\end{tabular}

Dats are expressed as mesns \pm standary deriations of three deterninutions: n.d $=$ not determined.

tained were compared with those reported in the literature $\mathrm{e}^{21,22)}$ and standards. To our knowledge, this is the first report of the isolation of compound 7 from Solidago cancdensis.

All isolated compounds were evaluated for their in vitso cytotoxic activity against human lung cancer $\mathrm{A} 549$, colon cancer DLD-I and normal fibroblasts, WSI cell lines. Etoposide and 5-fluorouracil was used as positive controls. As presented in Table 2 , only compound 1 was found to be active against $\mathrm{A} 549\left(\mathrm{IC}_{50}: 13 \pm 2 \mu \mathrm{M}\right), \mathrm{DLD}-1\left(\mathrm{IC}_{50}: 26 \pm 2 \mu \mathrm{M}\right)$ and 'WSI $\left(1 \mathrm{C}_{80}: 17 \pm 1 \mu_{\mathrm{M}}\right)$ cell lines.

Acknouledgments The unthors would like to thank Maxime Lebrun and Carole Grenon for technical assistance. This work was sapportet by the Fond Québecouis de Recherche sur la Nature et les Technologies (TQRNT) n.

References

1) Thiem B., Wesolowska M. Skrzypezak L . Budzianowski J, Acza Pol. Phamn, 58, 277-281/2001).

2) Apátí P., Szentminályi K, Kristo \$z. T., Papp I. Vinkler P., Szoke E,
Kéry A. I. Pramosdcett, Biomed, 32, 1045-1053 13003)

3) Krepinsky J. Hetout V. Chem. Commith, 27, 2459 2462 (1962)

4) Kalemba D., Phurnazie, 47, 471 - $472(1992)$

5) Bohlmann F. Fritz U. King R. M., Robinson If, Phwocitemisery, 19 $2655-2661$ (1980).

6) Anthonsen T, McCabe P. H.. McCrindle R., Murray R. D. H., Tefrzhe Afwn. 25, 2233-2239)(1969)

3) Reznicel 6 . Jurenitsch I., Kabelka W. Korhanmer S., Haslinger E, Viller K., Planta Med. 56, $554(1990)$.

8) Roussean J." "Ftudes athnobotaniques ąuébecoises: Le follkiar botanique de Caughewaga " Contributions de l'Institut botaniçte de PUniversité de Mentréal, 55. Les Presses de l"Universite de Montréal, Montrèal Canada. 1945, pp. T-72.

9) Arnason T. Hebda R. 3, Johus T., Cam, J. Bot, 59, $2189-2325$ (1981).

(0) Snith H. H. "Ethnobotany of the Fotest Potawatomi Indians," Bulletin of the Public Museum of the City of Mitwaukee 7, Milwatkee, United States, 1933 , p. 53.

11) Moerman D. E. "Native Amerikan Ethnobotany," 3rd ed., Timber Press Inc. Portland, United States, 2000, p. 536.

12) Turner N. J., Bouchard R., Kennedy D. 1, D, "Ethmolvotany of the Okanagan-Colville Indians of British Colunbin and Washington," British Columbia Provincial Museum, Ocoasional Paper Seties, 21. $1980,0.84$

13) O'Brien J. Wilson I., Otton I., Pognan E. Fur. I Biochem, 267. $5421-5426(2000)$.

14) Schmeda-Hirschmann G., Rodrigtuez $\mathrm{J}$, Astudillo L.. I. Ethrophummacol. $81,111-115(2002)$

15) Rodriguez J. A., Theodiloz C., Sánchez M., Razmilie I., SctmedaHirschmann G., Life Sci., 77, $2193-2205$ (2005).

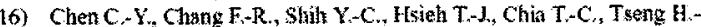
$Y$, Chen $\mathrm{H}, \mathrm{C}$, Chen S.-1, Hsu $\mathrm{M}, \mathrm{C}$, Wu Y.C., J, Nat, Prad, 63. $1475-1478(2000)$

17) Zdero C. Bohlmann F. King R. M., Phyzochemistry, 30, 1591-1595 (1991).

18) Scia E, Ribeiro A. Alves T M A., Romanha A. J., de Souza Fillo J. D., Cordell G. A., Zani C. L. Phytochenistry, 64. 1125 1131 (2003).

14) La T. Vargas D. Franzblau $\mathrm{S}$. G., Fischer N, H., Phrochemixtry, 38 . $451-456(1995)$

20) Vila R. Mundina M., Toni F. Furlán R.. Zachino $\mathrm{S}$, Casantwa J. Cantgueral S, Plonta Afed, 68, 164-167(2002).

21) Tatefuji T, lzuní N., Ohta T, Arai S, Ikeda M., Kurimoto M., Biof. Pharm. Bail., 19,966-970(1996).

22) Tolonen A., Joutsamo T., Mattla S., Kämämänen I. Jalonen 3.,Phytochem. Arkt. 13, 316 - $328(2002)$ 


\section{CHAPITRE IV}

\section{Antioxidant and anti-inflammatory activities of methanol extracts from} Solidago canadensis

Article en préparation pour Journal of Ethnopharmacology. 


\section{Résumé}

Le Solidago canadensis L. est une plante herbacée de la famille des Astéracées. En Amérique du Nord, cette plante était utilisée en médecine traditionnelle amérindienne pour traiter la douleur, les brûlures, les ulcères, la fièvre et les troubles du foie et de l'intestin. Dans le but de valoriser la biomasse de la forêt boréale par l'étude de l'activité biologique de composés d'origine naturelle, des extraits de fleurs, de feuilles et de tiges de Solidago canadensis ont été étudiés. Les extraits méthanoliques de fleurs, de feuilles et de tiges ont montré des propriétés antioxydantes avec des valeurs ORAC de $2.7 \pm 0.9 \mu \mathrm{mol} \mathrm{TE} / \mathrm{mg}$ pour les fleurs, $10.0 \pm 0.2 \mu \mathrm{mol} \mathrm{TE} / \mathrm{mg}$ pour les feuilles et $3.6 \pm 0.8 \mu \mathrm{mol} \mathrm{TE} / \mathrm{mg}$ pour les tiges. L'extrait méthanolique de fleurs a aussi montré une activité anti-inflammatoire en inhibant la production d'oxyde nitrique de macrophages RAW 264.7 activés avec du LPS (IC $50: 8 \pm$ $2 \mu \mathrm{g} / \mathrm{mL}$ ). Cependant, les extraits de feuilles et de tiges sont inactifs. Le fractionnement de l'extrait de fleurs a mené à l'isolation de cinq dérivés de l'acide caffeoylquinique connus. L'acide 3,4-di-O-caffeoylquinique est rapporté pour la première fois dans le Solidago canadensis. L'activité anti-inflammatoire des composés isolés a été évaluée, mais ces composés sont inactifs. 


\title{
Antioxidant and anti-inflammatory activities of methanol extracts from Solidago canadensis
}

\author{
Marie-Eve Bradette-Hébert, André Pichette, Vakhtang Mshvildadze, Jean Legault* \\ Laboratoire LASEVE, Université du Québec à Chicoutimi, 555, boulevard de 1'Université, \\ Chicoutimi, Québec, Canada, G7H 2B1.
}

Keywords: Solidago canadensis L., Asteraceae, anti-inflammatory, antioxidant, isolation, caffeoylquinic acids

*Address reprint requests to Dr J. Legault

Tel. 001 (418) 545-5011. Fax: 001 (418) 545-5012.

E-mail : Jean_Legault@uqac.ca 


\begin{abstract}
Solidago canadensis L. is an herbaceous plant of the family of Asteraceae. In North America, this plant has been used in native medicine for the treatment of pain, burns, ulcers, fever, gastrointestinal and liver diseases. Flowers, leaves and stems methanol extracts have shown antioxidant activities with ORAC values of $2.7 \pm 0.9 \mu \mathrm{mol} \mathrm{TE} / \mathrm{mg}$ for flowers, $10.0 \pm 0.2 \mu \mathrm{mol} \mathrm{TE} / \mathrm{mg}$ for leaves and $3.6 \pm 0.8 \mu \mathrm{mol} \mathrm{TE} / \mathrm{mg}$ for stems. The flowers extract have also shown an anti-inflammatory activity $\left(\mathrm{IC}_{50}: 8 \pm 2 \mu \mathrm{g} / \mathrm{mL}\right)$ on LPSactivated RAW 264.7 macrophages nitric oxide inhibition. However, leaves and stems methanol extracts were found to be inactive. Through fractionation of the flowers extract, 5 known caffeoylquinic acid derivatives were isolated. To our knowledge, compound 5 (3,4di-O-caffeoylquinic acid) is reported for the first time in Solidago canadensis. All isolated compounds were found to be inactive on LPS-activated RAW 264.7 macrophages nitric oxide inhibition.
\end{abstract}




\section{Introduction}

Solidago canadensis L. is an Asteraceae widely distributed across North America, occurring in almost every state in United States and throughout Canada. Solidago canadensis was used in American native medecine to treat pain (Rousseau, 1945), burns, ulcers (Arnason et al., 1981), fever (Moerman, 2000), gastrointestinal (Turner et al., 1980; Moerman, 2000) and liver (Moerman, 2000) diseases. Anti-inflammatory and antioxidant actions have been reported for extracts of the genus Solidago (Arens-Corell and Okpanyi, 1990; Leuschner, 1995). Previous studies on Solidago canadensis herbs extracts reported DPPH and luminol free radical scavenging antioxidant activities (Apáti et al., 2003; Papp et al., 2004). Furthermore, roots where demonstrated active when tested for DPPH free radical scavening, NBT/XO superoxide scavenging and DCF/AAPH peroxyl radical scavenging (McCune and Johns, 2002). However, to our knowledge, no antioxidant activity has been reported for Solidago canadensis flowers, leaves and stems. The genus Solidago contain numerous interesting secondary metabolites such as: flavonoids, phenolic acids and glucosides, polysaccharides, diterpenes, triterpenoid saponosides, tannins, essential oils and others (Thiem et al., 2001). Previous phytochemical studies of Solidago canadensis reported the presence of flavonoids (Krepinsky and Herout, 1962; Apáti et al., 2003), phenolic acids (Kalemba, 1992), sesquiterpenes (Bohlmann et al., 1979), diterpenes (Anthonsen et al., 1969; Bohlmann et al., 1979) and saponins (Reznicek et al., 1990).

In this study, we evaluate antioxidant and anti-inflammatory activities of flowers, leaves and stems methanol extracts of Solidago canadensis. 


\section{Materials and methods}

\subsection{General experimental procedures}

NMR spectra were recorded in methanol- $d_{4}$ on a Bruker Avance 400 spectrometer ( 5 mm QNP with Z-gradient probe) operating at $400.13 \mathrm{MHz}\left({ }^{1} \mathrm{H}\right)$ or $100.61 \mathrm{MHz}\left({ }^{13} \mathrm{C}\right)$. Chemical shifts were referenced relative to the corresponding residual solvent signals $(\delta$ 3.31/49.0 ppm, respectively). The accurate mass determination was carried out with an Applied Biosystems QSTAR XL. Hybrid LC/MS/MS system. All HPLC separations were performed on a preparative Agilent 1100 series with a ZORBAX ODS column C18 (2.1 x $25 \mathrm{~cm} ; 7 \mu \mathrm{m}$ ) at a flow rate of $16 \mathrm{~mL} / \mathrm{min}$. Compounds were detected by $\mathrm{UV}$ absorption at $254 \mathrm{~nm}$. For all $\mathrm{HPLC}$ procedures, solvent $\mathrm{A}$ was $\mathrm{H}_{2} \mathrm{O}+0.1 \% \mathrm{HCOOH}$ and solvent B was ACN $+0.1 \%$ HCOOH. Silica gel 60 (230-400 Mesh, Silicycle), Diaion HP-20 (Supelco) and silica gel $60 \mathrm{C} 18$ (230-400 Mesh, EMD) were used for column chromatography. The solvents were purchased from EMD. Thin-layer chromatography (TLC) was performed on silica gel $60 \mathrm{~F}_{254}$ aluminium sheets (Silicycle) using EtOAc-MeOH- $\mathrm{H}_{2} \mathrm{O}(100: 16.5: 13.5)$ as solvent system. Detection of the phenolic compounds was carried out by spraying TLC plates with NP/PEG reagent (1\% diphenylboric acid 2-aminoethylester in methanol and 5\% polyethylene glycol in ethanol) and observing under UV light before and after revelation (254 and $365 \mathrm{~nm}$ ). 


\subsection{Plant material}

The flowers, leaves and stems of Solidago canadensis L. were collected in september 2004 at St-Félicien $\left(48^{\circ} 40^{\prime} \mathrm{N}, 72^{\circ} 27^{\prime} \mathrm{W}\right)$, Québec, Canada. The specimens were identified by Mr. Patrick Nadeau (Département des Sciences Fondamentales, Université du Québec à Chicoutimi, Québec, Canada). A voucher specimen was deposited in the Louis-Marie Herbarium of Université Laval, Québec, Canada (QFA-492115).

\subsection{Extraction and isolation}

The air-dried flowers, leaves and stems of Solidago canadensis $(25 \mathrm{~g})$ were extracted with methanol $(300 \mathrm{~mL})$ in hot condition under reflux during 2 hours. The methanol extracts were evaporated on a rotary evaporator, under reduced pressure.

For the isolation steps, the air-dried flowers of Solidago canadensis (285 g) were extracted with methanol in hot condition $(3 \times 2.5 \mathrm{~L}$ ) and then, followed with methanol $80 \%$ ( $3 \times 2.5 \mathrm{~L}$ ) during 2 hours. The combined extracts were evaporated under reduced pressure, yielding a residue $(103.81 \mathrm{~g})$, which was suspended in water $(400 \mathrm{~mL})$ and successively extracted with dichloromethane ( $3 \times 200 \mathrm{~mL})$ and ethyl acetate $(6 \times 400 \mathrm{~mL})$, yielding dichloromethane, ethyl acetate and aqueous fractions. The aqueous fraction (66.13 g) of Solidago canadensis flowers was fractionated into three fractions (I-III) by chromatography over a silica gel column $(7 \times 60 \mathrm{~cm})$ using an isocratic solvent system of EtOAc-MeOH- 
$\mathrm{H}_{2} \mathrm{O}(100: 16.5: 13.5)$. The fraction II $(6.70 \mathrm{~g})$ containing the major constituents was divided into six fractions (A - F) using Diaion $(3.2 \times 40.5 \mathrm{~cm})$ by elution with $\mathrm{MeOH}-\mathrm{H}_{2} \mathrm{O}(20-80)$. Fraction B (1.03 g) was separated into nine fractions (B1 - B9) by passage over C18 silica gel column $(1.6 \times 46 \mathrm{~cm})$, eluting with $\mathrm{MeOH} 10 \%$. From B1 (214.2 mg), compounds 1 $(3.8 \mathrm{mg})$ and $2(9.3 \mathrm{mg})$ were isolated by preparative HPLC (6\% solvent B). Fractions B5 (135.1 $\mathrm{mg})$ and B6 (64.9 $\mathrm{mg})$ were combined and then, separated by preparative HPLC (16\% solvent B) to afford compounds $3(9.1 \mathrm{mg}), 4(7.0 \mathrm{mg})$ and $5(11.4 \mathrm{mg})$. Identification of these compounds was performed through NMR $\left({ }^{1} \mathrm{H},{ }^{13} \mathrm{C}, \mathrm{DEPT}, \mathrm{COSY}, \mathrm{HSQC}\right.$ and HMBC) and HR-ESI-MS analyses. The data obtained were compared with those reported in the literature (Tatefuji et al., 1996; Tolonen et al., 2002).

\subsection{Cell culture}

The murine macrophages RAW 264.7 (\#TIB-71) cell line was obtained from the American Type Culture Collection (ATCC, Manassas, USA). The RAW 264.7 cell line was grown in Dulbecco's modified Eagle's medium (Mediatech Cellgro®). Medium was supplemented with $10 \%$ fetal calf serum (Hyclone, Logan, USA), $1 \mathrm{X}$ solution of vitamins (Mediatech .Cellgro®), $1 \mathrm{X}$ sodium pyruvate (Mediatech Cellgro®), $1 \mathrm{X}$ non-essential amino acids (Mediatech Cellgro $\left.{ }^{\circledR}\right), 100 \mathrm{IU}$ of penicillin and $100 \mathrm{mg} / \mathrm{mL}$ of streptomycin (Mediatech Cellgroß). Cells were cultured at $37^{\circ} \mathrm{C}$ in a humidified atmosphere containing $5 \% \mathrm{CO}_{2}$. 


\subsection{Cytotoxic assay}

Exponentially growing cells were plated at a density of $5 \times 10^{3}$ cells per well in 96 -well microplates (BD Falcon) in $100 \mu \mathrm{L}$ of culture medium and were allowed to adhere for 16 hours before treatment. Then, the cells were incubated for 48 hours in the presence or absence of $100 \mu \mathrm{L}$ of increasing concentrations of extracts dissolved in culture medium and an appropriate solvent. The final concentration of solvent in the culture medium was maintained at $0.25 \%(\mathrm{v} / \mathrm{v})$ to avoid toxicity. Cytotoxicity was assessed using the resazurin reduction test (O'Brien et al., 2000). Fluorescence was measured on an automated 96-well Fluoroskan Ascent $\mathrm{Fl}^{\mathrm{TM}}$ plate reader (Labsystems) using an excitation wavelength of 530 $\mathrm{nm}$ and an emission wavelength of $590 \mathrm{~nm}$. Extracts are considered cytotoxic when inhibition of cell growth is observed.

\subsection{Measurement of the antioxidant activity by $\mathrm{ORAC}_{\mathrm{FL}}$ assay}

The oxygen radical antioxidant capacity (ORAC) assay was carried out on a Fluoroskan Ascent $\mathrm{F} 1^{\mathrm{TM}}$ plate reader (Labsystems). Quercetin was used as a positive control. The experiment was conducted at $37.5^{\circ} \mathrm{C}$ and $\mathrm{pH} 7.4$, with a blank sample in parallel. The fluorimeter was programmed to record the fluorescence of fluorescein every 30 seconds after addition of 2,2'-azobis (2-amidinopropane) dihydrochloride (AAPH). The final results were calculated by comparing the net areas under the fluorescein decay curves between the blank and the samples. Trolox was used as a control standard. ORAC values were expressed in micromoles of Trolox equivalents (TE) per milligram ( $\mu \mathrm{mol} \mathrm{TE} / \mathrm{mg})$. 


\subsection{Measurement of anti-inflammatory activity by nitric oxide (NO) inhibition on LPS-activated RAW 264.7 macrophages}

Exponentially growing cells were plated in 24-well microplates (BD Falcon) at a density of $2 \times 10^{5}$ cells per well in $400 \mu \mathrm{L}$ of culture medium and were allowed to adhere overnight. Cells were then treated or not with positive control N(G)-nitro-L-arginine methyl ester $(\mathrm{L}-\mathrm{NAME})(250 \mu \mathrm{mol} / \mathrm{L}$ and $1 \mathrm{mmol} / \mathrm{L})$, or increasing concentrations of fractions or pure compounds dissolved in the appropriate solvents, and incubated at $37^{\circ} \mathrm{C}, 5 \% \mathrm{CO}_{2}$ for 24h. The final concentration of solvent in the culture medium was maintained at $0.5 \%(\mathrm{v} / \mathrm{v})$ to avoid solvent toxicity. Cells were then stimulated with $10 \mu \mathrm{g} / \mathrm{mL}$ lipopolysaccharide (LPS). After $24 \mathrm{~h}$, cell-free supernatants were collected and stored at $-80^{\circ} \mathrm{C}$ until NO determination using the Greiss reaction (Green et al., 1990) with minor sulphanilamide and $50 \mu \mathrm{L}$ of $0.1 \% \mathrm{~N}$-1-naphtylethylenediamine dihydrochloride in $2.5 \% \mathrm{H}_{3} \mathrm{PO}_{4}$ at room temperature for $20 \mathrm{~min}$. Absorbance at $540 \mathrm{~nm}$ was then measured using an automated 96 well Varioskan Ascent plate reader (Thermo Electron) and the presence of nitrite was quantified by comparison with an $\mathrm{NaNO}_{2}$ standard curve. All the samples were tested at the highest concentration without macrophages cytotoxicity. Anti-inflammatory activity was expressed as the concentration of drug inhibiting nitric oxide overproduction by $50 \%$ (IC50). 


\section{Results and Discussion}

\subsection{Extraction yields}

The air-dried flowers, leaves and stems of Solidago canadensis were extracted with methanol in hot condition under reflux. As shown in Table 1, the extraction yields are 0.14 $\mathrm{g} / \mathrm{g}$ for flowers, $0.18 \mathrm{~g} / \mathrm{g}$ for leaves and $0.09 \mathrm{~g} / \mathrm{g}$ for stems.

\subsection{Antioxidant activity of methanol extracts}

The antioxidant activity of flowers leaves and stems methanol extracts was assessed using the ORAC assay (Ou et al., 2001). As shown in Table 1, in comparison to quercetin, all extracts exhibited moderate antioxidant activities with ORAC values of $2.7 \pm 0.9 \mu \mathrm{mol}$ $\mathrm{TE} / \mathrm{mg}$ for flowers, $10.0 \pm 0.2 \mu \mathrm{mol} \mathrm{TE} / \mathrm{mg}$ for leaves and $3.6 \pm 0.8 \mu \mathrm{mol} \mathrm{TE} / \mathrm{mg}$ for stems. Hence, leaves methanol extract was found to possess the best antioxidant activity. Previous phytochemical studies of Solidago canadensis have shown antioxidant activity for herbs extracts (Apáti et al., 2003; Papp et al., 2004). These results support the ethnopharmacological use of Solidago canadensis in pathologies implying reactive oxygen species. 


\subsection{Macrophages cytotoxicity and anti-inflammatory activity of extracts}

The claimed effect of Solidago canadensis on inflammatory diseases and related disorders by the American native medicine was challenged by testing flowers, leaves and stems methanol extracts of Solidago canadensis for anti-inflammatory activity using LPSactivated RAW 264.7 macrophages nitric oxide (NO) inhibition. Stimulation of RAW 264.7 macrophages by LPS induces iNOS and overproduction of NO which can be detected and quantified photometrically by a simple colorimetric reaction (Green et al., 1990) as described in materials and methods. L-NAME, a NO synthase inhibitor, prevents the formation of NO in LPS-stimulated RAW 264.7 macrophages (Paul et al., 1997) and thus was used as positive control. First, the macrophages cytotoxicity of extracts was investigated. As shown in Table 2, the highest concentration without macrophages cytotoxicity is $10.8 \mu \mathrm{g} / \mathrm{mL}$ for flowers, $13.0 \mu \mathrm{g} / \mathrm{mL}$ for leaves and $111.0 \mu \mathrm{g} / \mathrm{mL}$ for stems methanol extracts. Flowers methanol extract of Solidago canadensis inhibited overproduction of NO with an $\mathrm{IC}_{50}$ of $8 \pm 2 \mu \mathrm{g} / \mathrm{mL}$. However, leaves and stems methanol extracts were found to be inactive. Thus, the flowers are the most interesting part of Solidago canadensis for anti-inflammatory activity. These results support the ethnopharmacological use of Solidago canadensis flowers in the treatment of inflammation diseases implying NO and peroxinitrite. 


\subsection{Isolation of compounds from the flowers extract and evaluation of anti-inflammatory activity}

Fractionation was carried out to characterize the active principles responsible of the anti-inflammatory activity of the flowers extract of Solidago canadensis. The extract was thus suspended into $\mathrm{H}_{2} \mathrm{O}$ and then partitioned successively with DCM and EtOAc. Because of his wealth and his simplicity, as shown by TLC, the aqueous fraction has been chose. Further fractionations have led to the isolation of five known caffeoylquinic acid derivatives (1-5) which are the major constituents of the aqueous fraction: neochlorogenic acid (1, 3-O-caffeoylquinic acid), chlorogenic acid (2, 5-O-caffeoylquinic acid), 4,5-di- $O$ caffeoylquinic acid (3), 3,5-di- $O$-caffeoylquinic acid (4) and 3,4-di- $O$-caffeoylquinic acid (5). To our knowledge, compound $\mathbf{5}$ is reported for the first time in Solidago canadensis. Caffeoylquinic acid derivatives have been previously reported to have several interesting therapeutic properties, which include reducing inflammation (Facino et al., 1993; Rastrelli et al., 1998); activities on some human leukocyte functions related to inflammatory mechanism such as monocyte migration and reducing of superoxide anion production (Peluso et al., 1995); antioxidative activities (Kwon et al., 2000; Kweon et al., 2001; Stewart et al., 2005); inhibitory activities on lipid peroxidation in mitochondria and microsomes of the liver (Kimura et al., 1984); and finally, anti-viral activity (Zhu et al., 1999). The anti-inflammatory activity of isolated compound was evaluated using LPSactivated RAW 264.7 macrophages nitric oxide (NO) inhibition. All isolated compounds were found to be inactive (data not presented). 
In summary, this study show that flowers, leaves and stems methanol extracts of Solidago canadensis posses antioxidant activities and flowers methanol extract posses antiinflammatory activity, which support ethnopharmacological use of Solidago canadensis in American native medicine. Isolation procedures of the aqueous fraction of flowers extract have led to the isolation of five known caffeoylquinic acid derivatives (1-5) which are the major constituents of the aqueous fraction. To our knowledge, compound $\mathbf{5}(3,4$-di- $O$ caffeoylquinic acid) is reported for the first time in Solidago canadensis. However, these isolated compounds are not responsible of the anti-inflammatory activity. Further isolation procedures should be done to find the active principle of flowers extract.

\section{Acknowledgments}

The authors would like to thanks Serge Lavoie for his help and suggestions, Carole Grenon for technical assistance, Angelique Longtin for cytotoxic and anti-inflammatory assays and Karl Girard Lalancette for antioxidant assays. This work was supported by Action Concertée FQRNT - Fonds de la recherche forestière du Saguenay - Lac-Saint-Jean. 


\section{References}

Apáti, P., Szentmihályi, K., Kristo, Sz.T., Papp, I., Vinkler, P., Szoke, É., Kéry, Á., 2003. Herbal remedies of Solidago - correlation of phytochemical characteristics and antioxidative properties. Journal of Pharmaceutical and Biomedical Analysis 32, 10451053.

Arens-Corell, M., Okpanyi, S.N., 1990. anti-inflammatory and analgesic actions of a model anit-rheumatic phytotherapeutic fixed combination drug: Phytodolor N. Planta Medica 56, 656-657.

Arnason, T., Hebda, R.J., Johns, T., 1981. Use of plants for food and medicine by Native Peoples of eastern Canada. Canadian Journal of Botany 59, 2189-2325.

Anthonsen, T., McCabe, P.H., McCrindle, R., Murray, R.D.H., 1969. Constituents of Solidago species. Tetrahedron 25, 2233-2239.

Bohlmann, F., Fritz, U., King, R.M., Robinson, H., 1980. Sesquiterpene and diterpene derivatives from Solidago species. Phytochemistry 19, 2655-2661.

Esposito, E., Rotilio, D., Di Matteo, V., Di Giulio, C., Cacchio, M., Algeri, S., 2002. A review of specific dietary antioxidants and the effects on biochemical mechanisms related to neurodegenerative processes. Neurobiology of Aging 23, 719-735.

Facino, R.M., Carini, M., Aldini, G., Marinello, C., Arlandini, E., Franzoi, L., Colombo,. M., Pietta, P., Mauri, P., 1993. Direct characterization of caffeoyl esters with antihyaluronidase activity in crude extracts from Echinacea angustifolia roots by fast atom bombardment tandem mass spectrometry. Il Farmaco 48,1447-1461.

Finkel, T., Holbrook, N.J., 2000. Oxidants, oxidative stress and the biology of ageing. Nature 408, 239-247.

Frère Marie-Victorin, "Flore Laurentienne" Troisième édition, Les Presses de 1'Université de Montréal, Montréal, Canada, 1995, p.601.

Green, S.J., Meltzer, M.S., Hibbs Jr, J.B., Nacy, C.A., 1990. Activated macrophages destroy intracellular Leishmania major amastigotes by an L-arginine-dependant killing mechanism. The Journal of Immunology 144, 278-283.

Kalemba, D., 1992. Phenolic acids in four Solidago species. Pharmazie 47, 471-472. 
Kim, Y., Han, M.S., Lee, J.S., Kim, J., Kim, Y.C., 2003. Inhibitory phenolic amides on lipopolysaccharide-induced nitric oxide production in RAW 264.7 cells from Beta vulgaris var. cicla seeds. Phytotherapy Research 17, 983-985.

Kimura, Y., Okuda, H., Okuda, T., Hatano, T., Agata, I., Arichi, S., 1984. Studies on the activities of tannins and related compounds; V. Inhibitory effects on lipid peroxidation in mitochondria and microsomes of liver. Planta Medica 50, 473-477.

Krepinsky, J., Herout, V., 1962. Isolation of terpenic compounds from Solidago canadensis L. Chemical Communications 27, 2459-2462.

Kweon, M.-H., Hwang, H.-J., Sung, H.-C., 2001. Identification and antioxidant activity of novel chlorogenic acid derivatives from Bamboo (Phyllostachys edulis). Journal of Agriculture and Food Chemistry 49, 4646-4655.

Kwon, H.J., Kang, M.J., Kim, H.J., Choi, J.S., Paik, K.J., Chung, H.Y., 2000. Inhibition of NFkappaB by methyl chlorogenate from Eriobotrya japonica. Molecules and Cells 10, 241-246.

Leuschner, J., 1995. Anti-inflammatory, spasmolytic and diuretic effects of a commercially available Solidago gigantea herb. extract. Arzneimittel-Forschung Drug Research 45, 165 168.

Liang, Y.-C., Huang, Y.-T., Tsai, S.-H., Lin-Shiau, S.-Y., Chen, C.-F., Lin, J.-K., 1999. Suppression of inducible cyclooxygenase and inducible nitric oxide synthase by apigenin and related flavonoids in mouse macrophages. Carcinogenesis 20, 1945-1952.

McCune, L.M., Johns, T., 2002. Antioxidant activity in medicinal plants associated with the symptoms of diabetes mellitus used by the Indigenous Peoples of the North American boreal forest. Journal of Ethnopharmacology 82, 197-205.

Moerman, D.E., 2000. Native American ethnobotany. Third edition, Ed. Timber Press Inc., Portland, USA, p. 536.

O'Brien, J., Wilson, I., Orton, T., Pognan, F., 2000. Investigation of the Alamar Blue (resazurin) fluorescent dye for the assessment of mammalian cell cytotoxicity. European Journal of Biochemistry 267, 5421-5426.

Ou, B., Hampsch-Woodill, M., Prior R.L., 2001. Development and validation of an improved oxygen radical absorbance capacity assay using fluorescein as the fluorescent probe. Journal of Agricultural and Food Chemistry 49, 4619-4626.

Papp, I., Apáti, P., Andrasek, V., Blázovics, A., Balázs, A., Kursinszki, L., Kite, G.C., Houghton, P.J., Kéry, Á., 2004. Chromatographia 60, S93-S100. 
Paul, A., Bryant, C., Lawson, M.F., Chilvers, E.R., Plevin, R., 1997. Dissociation of lipopolysaccharide-mediated induction of nitric oxide synthase and inhibition of DNA synthesis in RAW 264.7 macrophages and rat aortic smooth muscle cells. British Journal of Pharmacology 120, 1439-1444.

Peluso, G., De Feo, V., De Simone, F., Bresciano, E., Vuotto, M.L., 1995. Studies on the inhibitory effects of caffeoylquinic acids on monocyte migration and superoxide ion production. Journal of Natural Products 58, 639-646.

Rastrelli, L., Saravia, A., Hernandez, M., De Simone, F., 1998. Antiinflammatory activityguided fractionation of Gnaphalium stramineum. Pharmaceutical Biology 36, 315-319.

Reznicek, G., Jurenitsch, J., Kubelka, W., Korhammer, S., Haslinger, E., Hiller, K., 1990. The first spectroscopically confirmed saponins from Solidago canadensis. Planta Medica 56,554

Rousseau, J., 1945. Études ethnobotaniques québécoises: Le folklore botanique de Caughnawaga. Contributions de l'Institut botanique de l'Université de Montréal 55, 7-72 (pp.65).

Stewart, A.J., Mullen, W., Crozier, A., 2005. On-line high-performance liquid chromatography analysis of the antioxidant activity of phenolic compounds in green and black tea. Molecular Nutrition and Food Research 49, 52-60.

Tatefuji, T., Izumi, N., Ohta, T., Arai, S., Ikeda, M., Kurimoto, M., 1996. Isolation and identification of compounds from Brazilian propolis which enhance macrophage spreading and mobility. Biological and Pharmaceutical Bulletin 19, 966-970.

Thiem, B., Wesolowska, M., Skrzypczak, L., Budzianowski, J., 2001. Phenolic compounds in two Solidago L. species from in vitro culture. Acta Poloniae Pharmaceutica 58, 277-281.

Tolonen, A., Joutsamo, T., Mattlla, S., Kämäräinen, T., Jalonen, J., 2002. Identification of isomeric dicaffeoylquinic acids from Eleutherococcus senticosus using HPLCESI/TOF/MS and ${ }^{1}$ H-NMR methods. Phytochemical Analysis 13, 316-328.

Turner, N.J., Bouchard, R., Kennedy, D.I.D., 1980. Ethnobotany of the Okanagan-Colville Indians of British Columbia and Washington, British Columbia Provincial Museum, Occasional Paper Series No.21, p.84.

Vamvakas, S., Schmidt, H.H.H.W., 1997. Just say NO to cancer? Journal of the National Cancer Institute 89, 406-407.

Zhu, K., Cordeiro, M.L., Atienza, J., Robinson Jr., W.E., Chow, S.A., 1999. Irreversible inhibition of human immunodeficiency virus type 1 integrase by dicaffeoylquinic acids. Journal of Virology 73, 3309-3316. 
Table 1.

Extraction yields and antioxidant activity of methanol extracts of Solidago canadensis.

\begin{tabular}{|c|c|c|}
\hline Plant part & $\begin{array}{l}\text { Yield } \\
(\mathrm{g} / \mathrm{g})^{\mathrm{a}}\end{array}$ & $\begin{array}{c}\text { ORAC value } \\
(\mu \mathrm{mol} \mathrm{TE} / \mathrm{mg})^{b}\end{array}$ \\
\hline Flowers & 0.14 & $2.7 \pm 0.9$ \\
\hline Leaves & 0.18 & $10.0 \pm 0.2$ \\
\hline Stems & 0.09 & $3.6 \pm 0.8$ \\
\hline \multicolumn{2}{|c|}{ Quercetin } & $17 \pm 2$ \\
\hline
\end{tabular}

${ }^{\mathrm{a}} \mathrm{g}$ solid extract/g dried biomass.

${ }^{b}$ Data are expressed as means \pm standard deviations of three determinations.

TE: Trolox equivalent.

Table 2.

Highest concentration without macrophages cytotoxicity and anti-inflammatory activity of methanol extracts of Solidago canadensis.

\begin{tabular}{ccc}
\hline Plant part & $\begin{array}{c}\text { Highest concentration without } \\
\text { macrophages cytotoxicity } \\
(\mu \mathrm{g} / \mathrm{mL})\end{array}$ & $\begin{array}{c}\text { Anti-inflammatory activity } \\
\text { IC }_{\mathbf{5 0}} \\
(\mu \mathrm{g} / \mathrm{mL})^{\mathbf{a}}\end{array}$ \\
\hline Flowers & 10.8 & $8 \pm 2$ \\
\hline Leaves & 13.0 & inactive \\
\hline Stems & 111.0 & inactive \\
\hline
\end{tabular}

${ }^{a}$ Data are expressed as means \pm standard deviations of three determinations. 


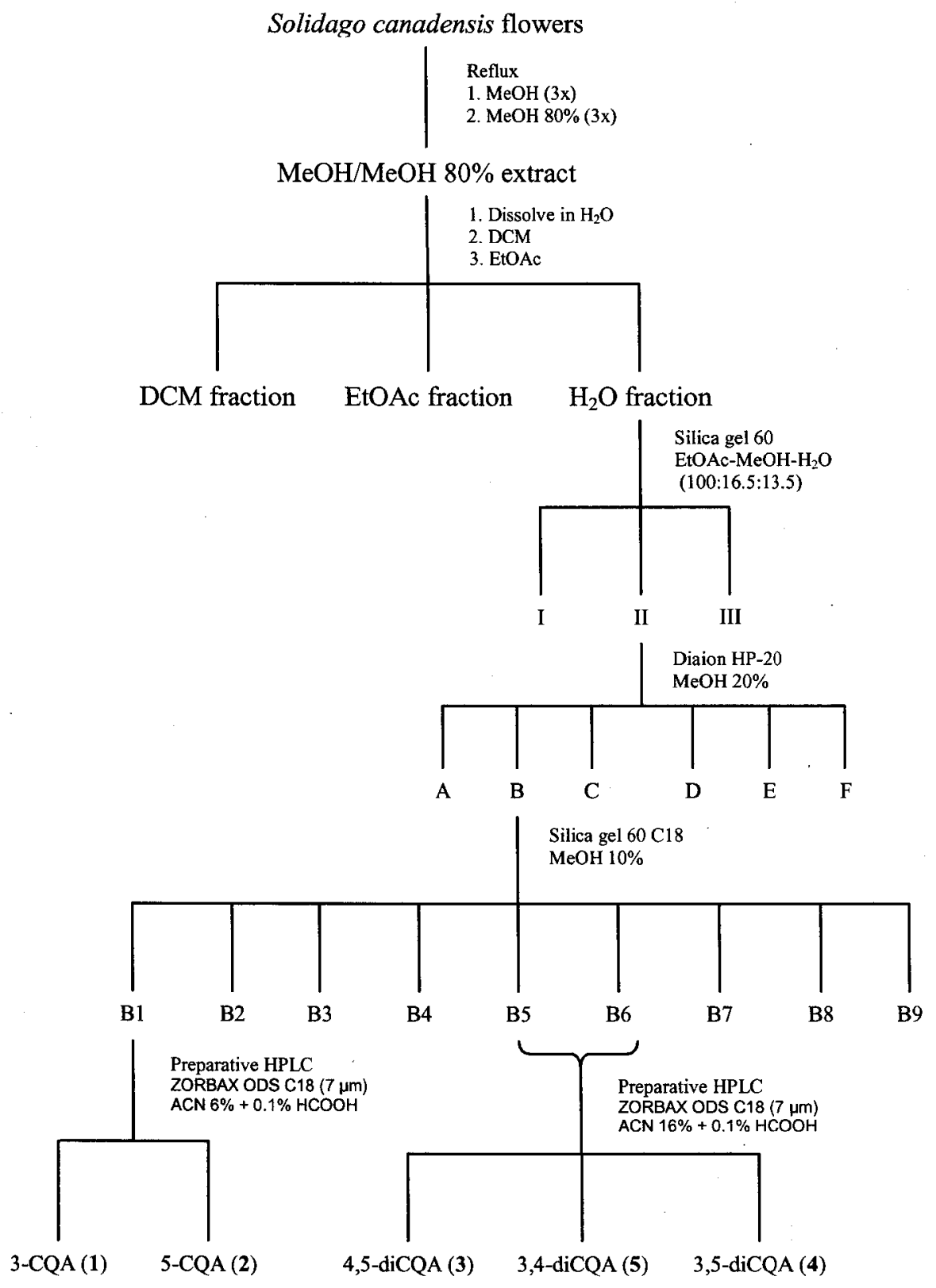

Fig. 1. Fractionation of Solidago canadensis flowers. 

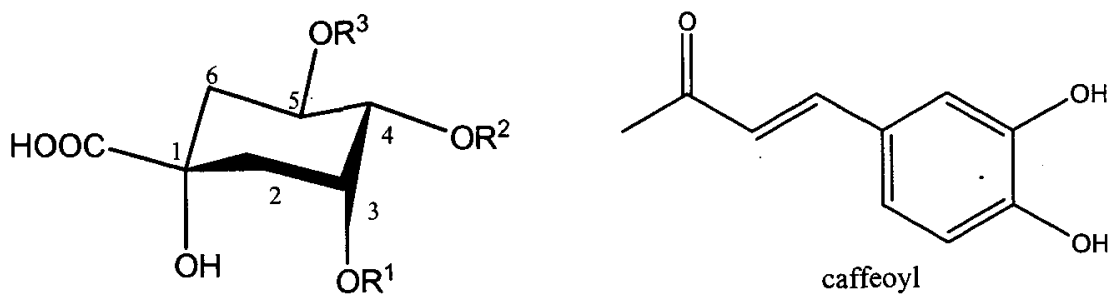

1: $\mathrm{R}^{1}=$ caffeoyl, $\mathrm{R}^{2}=\mathrm{H}, \mathrm{R}^{3}=\mathrm{H}$

2: $\mathrm{R}^{1}=\mathrm{H}, \mathrm{R}^{2}=\mathrm{H}, \mathrm{R}^{3}=$ caffeoyl

3: $\mathrm{R}^{1}=$ caffeoyl, $\mathrm{R}^{2}=$ caffeoyl, $\mathrm{R}^{3}=\mathrm{H}$

4: $\mathrm{R}^{1}=$ caffeoyl, $\mathrm{R}^{2}=\mathrm{H}, \mathrm{R}^{3}=$ caffeoyl

5: $R^{1}=H, R^{2}=$ caffeoyl, $R^{3}=$ caffeoyl

Fig. 2. Molecular structures of isolated compounds from aqueous extract of Solidago canadensis flowers. 
CHAPITRE V

\section{ÉTAT D'AVANCEMENT DU PROJET}




\section{5. État d'avancement du projet}

\subsection{Introduction}

Plusieurs espèces de la forêt boréale ont été rapportées dans la littérature pour des applications anti-inflammatoires en médecine traditionnelle amérindienne. Les principales espèces utilisées étaient Abies balsamea, Larix laricina, Ledum groenlandicum, Picea glauca, Picea mariana, Pinus banksiana, Populus balsamifera, Populus tremuloides, Solidago canadensis, Vaccinium angustifolium et Vaccinium myrtilloides (Moerman, 2000). Ces espèces ont fait l'objet d'un criblage afin d'évaluer leur activité antiinflammatoire dans le but de traiter des malaises associés à cette réaction de défense immunitaire. Les activités antioxydante et anti-cancéreuse ont également été évaluées afin de maximiser les retombées de cette étude. 


\subsection{Préparation des espèces végétales}

Les espèces sélectionnées (Moerman, 2000) ont d'abord été récoltées (Tableau 2), triées, séchées à l'air libre et broyées. Chaque matrice végétale a ensuite été extraite par Soxhlet avec du méthanol $(350 \mathrm{~mL})$. Chaque extrait a été évaporé sous pression réduite et séché sous vide.

Tableau 2. Données relatives à la récolte des espèces sélectionnées

\begin{tabular}{|c|c|c|c|}
\hline Espèce & Partie & Endroit & Date \\
\hline \multirow{4}{*}{$\begin{array}{l}\text { Abies balsamea } \\
\text { (Linné) P. Miller }\end{array}$} & aiguilles & \multirow{4}{*}{$\begin{array}{l}\text { Réserve faunique des } \\
\text { Laurentides }\end{array}$} & \multirow{4}{*}{12 juillet 2003} \\
\hline & branches & & \\
\hline & $\begin{array}{c}\text { tronc avec écorces } \\
\text { écorces }\end{array}$ & & \\
\hline & racines & & \\
\hline \multirow{5}{*}{$\begin{array}{c}\text { Larix laricina } \\
\text { (Du Roi) K. Koch. }\end{array}$} & aiguilles & \multirow{5}{*}{$\begin{array}{l}\text { Réserve faunique des } \\
\text { Laurentides }\end{array}$} & \multirow{5}{*}{20 septembre 2004} \\
\hline & branches & & \\
\hline & tronc avec écorces & & \\
\hline & écorces & & \\
\hline & racines & & \\
\hline \multirow{3}{*}{ Ledum groenlandicum Oeder } & feuilles & \multirow{3}{*}{ St-Félicien } & \multirow{3}{*}{26 septembre 2004} \\
\hline & tiges & & \\
\hline & racines & & \\
\hline \multirow{4}{*}{$\begin{array}{c}\text { Picea glauca } \\
\text { (Moench) Voss }\end{array}$} & aiguilles & \multirow{4}{*}{ St-Félicien } & \multirow{4}{*}{26 septembre 2004} \\
\hline & $\begin{array}{l}\text { branches } \\
\text { tronc avec écorces }\end{array}$ & & \\
\hline & écorces & & \\
\hline & racines & & \\
\hline \multirow{5}{*}{$\begin{array}{c}\text { Picea mariana } \\
\text { (P. Miller) Britton, Sterns \& } \\
\text { Poggenburg }\end{array}$} & aiguilles & \multirow{5}{*}{$\begin{array}{l}\text { Réserve faunique des } \\
\text { Laurentides }\end{array}$} & \multirow{5}{*}{12 juillet 2003} \\
\hline & branches & & \\
\hline & tronc avec écorces & & \\
\hline & écorces & & \\
\hline & racines & & \\
\hline \multirow{5}{*}{ Pinus banksiana Lambert } & cônes & \multirow{5}{*}{$\begin{array}{l}\text { Réserve faunique des } \\
\text { Laurentides }\end{array}$} & \multirow{5}{*}{14 octobre 2004} \\
\hline & $\begin{array}{l}\text { aiguilles } \\
\text { branches }\end{array}$ & & \\
\hline & $\begin{array}{l}\text { branches } \\
\text { tronc avec écorces }\end{array}$ & & \\
\hline & écorces & & \\
\hline & racines & & \\
\hline \multirow{3}{*}{ Populus balsamifera Linné } & branches & \multirow{3}{*}{$\begin{array}{l}\text { Réserve faunique des } \\
\text { Laurentides }\end{array}$} & \multirow{3}{*}{20 septembre 2004} \\
\hline & tronc avec écorces & & \\
\hline & $\frac{\text { écorces }}{\text { racines }}$ & & \\
\hline \multirow{3}{*}{ Populus tremuloides Michaux } & branches & \multirow{3}{*}{$\begin{array}{l}\text { Réserve faunique des } \\
\text { Laurentides }\end{array}$} & \multirow{3}{*}{20 septembre 2004} \\
\hline & tronc avec écorces & & \\
\hline & écorces & & \\
\hline \multirow{3}{*}{ Solidago canadensis Linné } & fleurs & \multirow{3}{*}{ Laterrière } & \multirow{3}{*}{28 août 2003} \\
\hline & feuilles & & \\
\hline & tiges & & \\
\hline Vaccinium angustifolium Aiton & $\frac{\text { tiges }}{\text { racines }}$ & St-Félicien & 26 septembre 2004 \\
\hline Vaccinium myrtilloides Michaux & tiges & St-Félicien & 26 septembre 2004 \\
\hline & racines & & \\
\hline
\end{tabular}




\subsection{Résultats et discussion}

\subsection{1 Évaluation de l'activité anti-inflammatoire}

L'évaluation de l'activité anti-inflammatoire a été faite en fonction du pouvoir d'inhibition sur la production d'oxyde nitrique de macrophages activés (Green et al., 1990). La concentration maximale sans cytotoxicité sur les macrophages a d'abord été établie pour chaque extrait afin de pouvoir évaluer la production réelle d'oxyde nitrique des macrophages activés. Cette évaluation a été réalisée selon la méthode de réduction à la résazurine (O’Brien et al., 2000). La procédure expérimentale pour l'évaluation de la cytotoxicité des extraits sur les macrophages et l'activité anti-inflammatoire est présentée au chapitre IV. Plusieurs extraits ont démontré une cytotoxicité élevée. Ainsi, l'activité anti-inflammatoire de plusieurs extraits n'a pu être évaluée à des doses élevées. Les résultats sont présentés au Tableau 3. L'extrait de fleurs de Solidago canadensis se démarque en étant le seul à inhiber plus de $50 \%$ de la production d'oxyde nitrique et ce, à une concentration relativement faible (65 $\pm 3 \%$ d'inhibition à $10.8 \mu \mathrm{g} / \mathrm{mL})$. L'espèce possédant l'activité anti-inflammatoire la plus intéressante est le Solidago canadensis et 1'extrait de fleurs est le plus actif. 


\subsection{2 Évaluation de l'activité antioxydante}

L'évaluation de l'activité antioxydante a été réalisée avec la méthode ORAC (Ou et al., 2001). La méthodologie pour cette évaluation est présentée au chapitre IV. Tel que présenté au Tableau 4, certaines espèces se démarquent en étant plus actives que la quercétine $(17 \pm 2 \mu \mathrm{mol} \mathrm{TE} / \mathrm{mg})$, un composé reconnu pour son activité antioxydante élevée (Ou et al., 2002). Il est question de Picea mariana (aiguilles ( $28 \pm 5 \mu \mathrm{mol} \mathrm{TE} / \mathrm{mg}$ ), branches ( $21 \pm 5 \mu \mathrm{mol} \mathrm{TE} / \mathrm{mg})$, tronc avec écorces $(34 \pm 8 \mu \mathrm{mol} \mathrm{TE} / \mathrm{mg})$, écorces $(40 \pm 4$ $\mu \mathrm{mol} \mathrm{TE} / \mathrm{mg}$ ) et racines $(60 \pm 20 \mu \mathrm{mol} \mathrm{TE} / \mathrm{mg})$ ), Ledum groenlandicum (feuilles (25 \pm 1 $\mu \mathrm{mol} \mathrm{TE} / \mathrm{mg}$ ), tiges (46 $\pm 8 \mu \mathrm{mol} \mathrm{TE} / \mathrm{mg}$ ) et racines ( $44 \pm 7 \mu \mathrm{mol} \mathrm{TE} / \mathrm{mg})$ ), Abies balsamea (racines (42 $\pm 3 \mu \mathrm{mol} \mathrm{TE} / \mathrm{mg})$ ), Picea glauca (branches $(21 \pm 1 \mu \mathrm{mol} \mathrm{TE} / \mathrm{mg})$, tronc avec écorces $(27 \pm 1 \mu \mathrm{mol} \mathrm{TE} / \mathrm{mg}$ ) et écorces $(34 \pm 2 \mu \mathrm{mol} \mathrm{TE} / \mathrm{mg})$ ), Larix laricina (branches (26 $\pm 2 \mu \mathrm{mol} \mathrm{TE} / \mathrm{mg})$, tronc avec écorces $(19 \pm 2 \mu \mathrm{mol} \mathrm{TE} / \mathrm{mg})$ et écorces $(26 \pm 2 \mu \mathrm{mol}$ TE/mg)), Vaccinium myrtilloides (racines $(25.0 \pm 0.5 \mu \mathrm{mol} \mathrm{TE} / \mathrm{mg}$ )) et Pinus banksiana (cônes $(22 \pm 4 \mu \mathrm{mol} \mathrm{TE} / \mathrm{mg})$ ). Tous les extraits de Ledum groenlandicum et de Picea mariana possèdent une activité supérieure à celle observée pour la quercétine, il s'agit donc d'espèces très intéressantes au niveau antioxydant. Les résultats obtenus avec les feuilles et les tiges du Ledum groenlandicum sont rapportés dans un article publié dans Journal of Ethnopharmacology (Dufour, D., Pichette, A., Mshvildadze, V., Bradette-Hébert, M.E., Lavoie, S., Longtin, A., Laprise, C., Legault, J., 2007. Antioxidant, anti-inflammatory and anticancer activities of methanolic extracts from Ledum groenlandicum Retzius. Journal of Ethnopharmacology 111, 22-28). 


\subsection{3 Évaluation de l'activité anticancéreuse}

L'évaluation de la cytotoxicité des extraits a été évaluée sur deux lignées cellulaires cancéreuses humaines, un carcinome du poumon (A-549) et un adénocarcinome du colon (DLD-1). La cytotoxicité des extraits a également été testée sur des fibroblastes humains normaux (WS1) afin d'évaluer les impacts sur des cellules saines (Tableau 5). L'activité anticancéreuse a été évaluée in vitro selon le test de réduction à la résazurine $\left(\mathrm{O}^{\circ}\right.$ brien et al., 2000). La procédure expérimentale pour l'évaluation de l'activité anticancéreuse est présentée au chapitre III. Selon les critères du National Cancer Institute, un extrait est considéré actif lorsque son $\mathrm{IC}_{50}$ est inférieure à $100 \mu \mathrm{g} / \mathrm{mL}$ (Boyd, 1997). Parmi tous les extraits testés, les racines de Pinus banksiana (A-549: $50 \pm 4 \mu \mathrm{g} / \mathrm{mL}$; DLD-1: $42 \pm 3$ $\mu \mathrm{g} / \mathrm{mL}$; WS1: $46 \pm 3 \mu \mathrm{g} / \mathrm{mL}$ ), les écorces d'Abies balsamea (A-549: $88 \pm 9 \mu \mathrm{g} / \mathrm{mL}$; DLD-1: $92 \pm 9 \mu \mathrm{g} / \mathrm{mL} ; \mathrm{WS} 1: 70 \pm 8 \mu \mathrm{g} / \mathrm{mL}$ ) et le tronc avec écorces de Larix laricina (A-549: 112 $\pm 9 \mu \mathrm{g} / \mathrm{mL}$; DLD-1: $96 \pm 13 \mu \mathrm{g} / \mathrm{mL}$; WS1: $105 \pm 4 \mu \mathrm{g} / \mathrm{mL}$ ) sont les extraits qui possèdent les activités les plus intéressantes. Cependant, ces $\mathrm{IC}_{50}$ sont élevées par rapport aux résultats obtenus avec l'étoposide (A-549: $1.1 \pm 0.1 \mu \mathrm{g} / \mathrm{mL}$; DLD-1: $4.8 \pm 0.8 \mu \mathrm{g} / \mathrm{mL}$ ) et le 5fluorouracil (A-549: $4.8 \pm 0.6 \mu \mathrm{g} / \mathrm{mL}$; DLD-1: $11 \pm 2 \mu \mathrm{g} / \mathrm{mL}$ ), des anticancéreux reconnus. 


\subsection{Résultats}

Tableau 3. Évaluation de l'activité anti-inflammatoire d'espèces de la forêt boréale.

\begin{tabular}{|c|c|c|c|}
\hline Espèce & Partie & $\begin{array}{c}\text { Concentration maximale } \\
\text { sans cytotoxicité sur les } \\
\text { macrophages } \\
(\mu \mathrm{g} / \mathrm{mL}) \\
\end{array}$ & $\begin{array}{c}\text { Inhibition NO à la } \\
\text { concentration maximale } \\
(\%)^{\mathrm{a}}\end{array}$ \\
\hline \multirow{5}{*}{$\begin{array}{l}\text { Abies balsamea } \\
\text { (Linné) P. Miller }\end{array}$} & aiguilles & 1.4 & $8 \pm 2$ \\
\hline & branches & 2.7 & $12 \pm 1$ \\
\hline & tronc avec écorces & 4.7 & $13.7 \pm 0.3$ \\
\hline & écorces & 2.6 & $8 \pm 2$ \\
\hline & racines & 13.0 & $2 \pm 1$ \\
\hline \multirow{5}{*}{$\begin{array}{c}\text { Larix laricina } \\
\text { (Du Roi) K. Koch. }\end{array}$} & aiguilles & 2.7 & inactif \\
\hline & branches & 2.6 & $18 \pm 1$ \\
\hline & tronc avec écorces & 5.0 & $26.9 \pm 0.5$ \\
\hline & écorces & 2.5 & $28 \pm 1$ \\
\hline & racines & 98.5 & $9 \pm 1$ \\
\hline \multirow{3}{*}{ Ledum groenlandicum Oeder } & feuilles & 97.9 & $13 \pm 1$ \\
\hline & tiges & 98.6 & $8 \pm 1$ \\
\hline & racines & 195.6 & inactif \\
\hline \multirow{5}{*}{$\begin{array}{l}\text { Picea glauca } \\
\text { (Moench) Voss }\end{array}$} & aiguilles & 1.4 & inactif \\
\hline & branches & 4.8 & $35 \pm 1$ \\
\hline & tronc avec écorces & 4.7 & $39 \pm 1$ \\
\hline & écorces & 5.0 & $18 \pm 1$ \\
\hline & racines & 102.9 & $22 \pm 1$ \\
\hline \multirow{5}{*}{$\begin{array}{c}\text { Picea mariana } \\
\text { (P. Miller) Britton, Sterns \& } \\
\text { Poggenburg }\end{array}$} & aiguilles & 2.2 & $6 \pm 2$ \\
\hline & branches & 2.3 & inactif \\
\hline & tronc avec écorces & 2.7 & $10.5 \pm 0.5$ \\
\hline & écorces & 5.4 & $11 \pm 3$ \\
\hline & racines & 50.0 & $18 \pm 1$ \\
\hline \multirow{6}{*}{ Pinus banksiana Lambert } & cônes & 2.5 & $29 \pm 1$ \\
\hline & aiguilles & 4.7 & $37.5 \pm 0.5$ \\
\hline & branches & 1.3 & $10.6 \pm 0.5$ \\
\hline & tronc avec écorces & 1.3 & $8 \pm 1$ \\
\hline & écorces & 2.5 & $20 \pm 1$ \\
\hline & racines & 13.0 & inactif \\
\hline \multirow{4}{*}{ Populus balsamifera Linné } & branches & 13.0 & $3 \pm 1$ \\
\hline & tronc avec écorces & 13.0 & inactif \\
\hline & écorces & 6.0 & $10 \pm 2$ \\
\hline & racines & 12.0 & $6 \pm 3$ \\
\hline \multirow{4}{*}{ Populus tremuloides Michaux } & branches & 13.0 & $4 \pm 1$ \\
\hline & tronc avec écorces & 13.0 & inactif \\
\hline & écorces & 6.0 & $6 \pm 2$ \\
\hline & racines & 12.0 & inactif \\
\hline \multirow{3}{*}{ Solidago canadensis Linné } & fleurs & 10.8 & $65+3$ \\
\hline & feuilles & 13.0 & $4 \pm 2$ \\
\hline & tiges & 111.0 & $21 \pm 1$ \\
\hline \multirow{2}{*}{ Vaccinium angustifolium Aiton } & tiges & 195.2 & inactif \\
\hline & racines & 51.0 & $13 \pm 1$ \\
\hline \multirow{2}{*}{ Vaccinium myrtilloides Michaux } & tiges & 25.0 & $8 \pm 3$ \\
\hline & racines & 199.5 & inactif \\
\hline
\end{tabular}

NO : Nitric oxide

${ }^{a}$ Moyenne de trois déterminations \pm déviation standard. 
Tableau 4. Évaluation de l'activité antioxydante d'espèces de la forêt boréale.

\begin{tabular}{|c|c|c|}
\hline Espèce & Partie & $\begin{array}{c}\text { ORAC }_{\mathbf{F L}} \\
(\mu \mathrm{mol} \mathrm{TE} / \mathrm{mg})^{a}\end{array}$ \\
\hline \multirow{5}{*}{$\begin{array}{l}\text { Abies balsamea } \\
\text { (Linné) P. Miller }\end{array}$} & aiguilles & $9 \pm 3$ \\
\hline & branches & $7 \pm 1$ \\
\hline & tronc avec écorces & $9.6 \pm 0.5$ \\
\hline & écorces & $3.4 \pm 0.5$ \\
\hline & racines & $42 \pm 3 . ? 7$ \\
\hline \multirow{5}{*}{$\begin{array}{c}\text { Larix laricina } \\
\text { (Du Roi) K. Koch. }\end{array}$} & aiguilles & $8.4 \pm 0.9$ \\
\hline & branches & 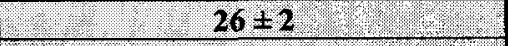 \\
\hline & tronc avec écorces & $19 \pm 2$ \\
\hline & écorces & $26+2$ \\
\hline & racines & $10 \pm 2$ \\
\hline \multirow{3}{*}{ Ledum groenlandicum Oeder } & feuilles & 20.7. \\
\hline & tiges & $4.76+8$ \\
\hline & racines & 4.047 \\
\hline \multirow{5}{*}{$\begin{array}{l}\text { Picea glauca } \\
\text { (Moench) Voss }\end{array}$} & aiguilles & $13.9 \pm 0.3$ \\
\hline & branches & $21+1$ \\
\hline & tronc avec écorces & $27 \pm 1$ \\
\hline & écorces & $34 \pm 2$ \\
\hline & racines & $11 \pm 1$ \\
\hline \multirow{5}{*}{$\begin{array}{c}\text { Picea mariana } \\
\text { (P. Miller) Britton, Sterns \& } \\
\text { Poggenburg }\end{array}$} & aiguilles & $28 \pm 5$ \\
\hline & branches & lint:? \\
\hline & tronc avec écorces & $34=8$ \\
\hline & écorces & $.00+4$ \\
\hline & racines & W' \\
\hline \multirow{6}{*}{ Pinus banksiana Lambert } & cônes & 17. \\
\hline & aiguilles & $9.1 \pm 0.9$ \\
\hline & branches & $6.7 \pm 0.8$ \\
\hline & tronc avec écorces & $9.7 \pm 0.8$ \\
\hline & écorces & n.d. \\
\hline & racines & $11 \pm 1$ \\
\hline \multirow{4}{*}{ Populus balsamifera Linné } & branches & $6.9 \pm 0.8$ \\
\hline & tronc avec écorces & $5.4 \pm 0.4$ \\
\hline & écorces & $10 \pm 1$ \\
\hline & racines & $4.3 \pm 0.6$ \\
\hline \multirow{4}{*}{ Populus tremuloides Michaux } & branches & $9.8 \pm 0.8$ \\
\hline & tronc avec écorces & $5.1 \pm 0.3$ \\
\hline & écorces & $6.0 \pm 0.5$ \\
\hline & racines & $7.8 \pm 0.8$ \\
\hline \multirow{3}{*}{ Solidago canadensis Linné } & fleurs & $2.7 \pm 0.9$ \\
\hline & feuilles & $10.0 \pm 0.2$ \\
\hline & tiges & $3.6 \pm 0.8$ \\
\hline \multirow{2}{*}{ Vaccinium angustifolium Aiton } & tiges & $8 \pm 1$ \\
\hline & racines & $5 \pm 1$ \\
\hline \multirow{2}{*}{ Vaccinium myrtilloides Michaux } & tiges & $6.3 \pm 0.8$ \\
\hline & racines & 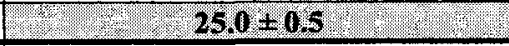 \\
\hline \multicolumn{2}{|c|}{ Quercétine } & $17 \pm 2$ \\
\hline
\end{tabular}

ORAC : Oxygen radical antioxidant activity; TE : Trolox equivalents; n.d.: non déterminé.

${ }^{a}$ Moyenne de trois déterminations \pm déviation standard. 
Tableau 5. Évaluation de l'activité anticancéreuse d'espèces de la forêt boréale.

\begin{tabular}{|c|c|c|c|c|}
\hline \multirow{2}{*}{ Espèce } & \multirow{2}{*}{ Partie } & \multicolumn{3}{|c|}{$\mathrm{IC}_{50}(\mu \mathrm{g} / \mathrm{mL})^{\mathrm{a}}$} \\
\hline & & A-549 & DLD-1 & WS1 \\
\hline \multirow{5}{*}{$\begin{array}{l}\text { Abies balsamea } \\
\text { (Linné) P. Miller }\end{array}$} & aiguilles & inactif & inactif & inactif \\
\hline & branches & inactif & inactif & inactif \\
\hline & tronc avec écorces & inactif & inactif & inactif \\
\hline & écorces & $88 \pm 9$ & $92 \pm 9$ & $70 \pm 8$ \\
\hline & racines & inactif & inactif & $55 \pm 3$ \\
\hline \multirow{5}{*}{$\begin{array}{c}\text { Larix laricina } \\
\text { (Du Roi) K. Koch. }\end{array}$} & aiguilles & inactif & inactif & inactif \\
\hline & branches & inactif & inactif & inactif \\
\hline & tronc avec écorces & $112 \pm 9$ & $96 \pm 13$ & $105 \pm 4$ \\
\hline & écorces & inactif & inactif & inactif \\
\hline & racines & inactif & inactif & inactif \\
\hline \multirow{3}{*}{$\begin{array}{c}\text { Ledum groenlandicum } \\
\text { Oeder }\end{array}$} & feuilles & inactif & inactif & inactif \\
\hline & tiges & inactif & inactif & inactif \\
\hline & racines & inactif & inactif & inactif \\
\hline \multirow{5}{*}{$\begin{array}{l}\text { Picea glauca } \\
\text { (Moench) Voss }\end{array}$} & aiguilles & inactif & inactif & inactif \\
\hline & branches & inactif & inactif & inactif \\
\hline & tronc avec écorces & inactif & inactif & inactif \\
\hline & écorces & inactif & inactif & inactif \\
\hline & racines & inactif & inactif & inactif \\
\hline \multirow{5}{*}{$\begin{array}{c}\text { Picea mariana } \\
\text { (P. Miller) Britton, } \\
\text { Sterns \& Poggenburg }\end{array}$} & aiguilles & inactif & inactif & inactif \\
\hline & branches & inactif & inactif & inactif \\
\hline & tronc avec écorces & inactif & inactif & inactif \\
\hline & écorces & inactif & inactif & inactif \\
\hline & racines & inactif & inactif & inactif \\
\hline \multirow{6}{*}{$\begin{array}{l}\text { Pinus banksiana } \\
\text { Lambert }\end{array}$} & cônes & inactif & inactif & inactif \\
\hline & aiguilles & inactif & inactif & inactif \\
\hline & branches & inactif & inactif & inactif \\
\hline & tronc avec écorces & inactif & inactif & inactif \\
\hline & écorces & inactif & inactif & inactif \\
\hline & racines & $50 \pm 4$ & $42 \pm 3$ & $46 \pm 3$ \\
\hline \multirow{4}{*}{$\begin{array}{c}\text { Populus balsamifera } \\
\text { Linné }\end{array}$} & branches & inactif & inactif & inactif \\
\hline & tronc avec écorces & inactif & inactif & inactif \\
\hline & écorces & inactif & inactif & inactif \\
\hline & racines & inactif & inactif & inactif \\
\hline \multirow{4}{*}{$\begin{array}{c}\text { Populus tremuloides } \\
\text { Michaux }\end{array}$} & branches & inactif & inactif & $91 \pm 7$ \\
\hline & tronc avec écorces & inactif & inactif & inactif \\
\hline & écorces & inactif & inactif & inactif \\
\hline & racines & inactif & inactif & inactif \\
\hline \multirow{3}{*}{$\begin{array}{c}\text { Solidago canadensis } \\
\text { Linné }\end{array}$} & fleurs & inactif & inactif & inactif \\
\hline & feuilles & inactif & inactif & inactif \\
\hline & tiges & inactif & inactif & inactif \\
\hline \multirow{2}{*}{$\begin{array}{c}\text { Vaccinium angustifolium } \\
\text { Aiton } \\
\end{array}$} & tiges & inactif & inactif & inactif \\
\hline & racines & inactif & inactif & inactif \\
\hline \multirow{2}{*}{$\begin{array}{c}\text { Vaccinium myrtilloides } \\
\text { Michaux }\end{array}$} & tiges & inactif & inactif & inactif \\
\hline & racines & inactif & inactif & inactif \\
\hline \multicolumn{2}{|c|}{ Etoposide } & $1.1 \pm 0.1$ & $4.8 \pm 0.8$ & - \\
\hline \multicolumn{2}{|c|}{ 5-fluorouracil } & $4.8 \pm 0.6$ & $11 \pm 2$ & - \\
\hline
\end{tabular}

${ }^{a}$ Moyenne de trois déterminations \pm déviation standard. 


\subsection{Conclusion}

Le criblage effectué au début du projet a permis de cibler des espèces démontrant certains potentiels bioactifs. Le Solidago canadensis est la seule espèce possédant une activité anti-inflammatoire intéressante. Toutes les espèces étudiées ont démontré une activité antioxydante. Cependant, le Ledum groenlandicum et le Picea mariana sont les espèces les plus intéressantes. En ce qui concerne l'activité anticancéreuse, les extraits d'Abies balsamea, de Larix laricina et de Pinus banksiana possédent le plus de potentiel. L'ensemble des résultats démontre l'intérêt de poursuivre des recherches visant à approfondir les composés responsables de ces activités. 


\section{CHAPITRE VI} CONCLUSION 


\section{Conclusion}

L'objectif principal de ce projet de recherche visait à valoriser la biomasse de la forêt boréale notamment par l'étude du potentiel anti-inflammatoire d'extraits et de composés issus de la forêt boréale. Ainsi, des plantes potentiellement anti-inflammatoires de la forêt boréale ont été sélectionnées en se basant sur la médecine traditionnelle amérindienne. Les différentes parties (fleurs, feuilles, tiges et racines) des plantes sélectionnées ont été extraites. Les activités anti-inflammatoire, antioxydante et anticancéreuse des différents extraits ont été évaluées. Au cours de ce projet de maîtrise, il a été démontré que les fleurs de Solidago canadensis possèdent une activité anti-inflammatoire. De plus, les fleurs, les feuilles et les tiges de Solidago canadensis ont montré une activité antioxydante. Par conséquent, ces résultats supportent l'utilisation ethnopharmacologique de cette plante par les peuples ancestraux de l'Amérique du Nord. L'extrait de fleurs de Solidago canadensis a été sélectionné et les composés majoritaires de la fraction aqueuse ont été isolés par chromatographie et HPLC préparatif. La caractérisation par résonance magnétique nucléaire et par spectrométrie de masse a mené à l'identification de ces composés. De la sorte, cinq dérivés connus d'acide caffeoylquinique ont été isolés. Toutefois, il s'avère que ces composés ne sont pas responsables de l'activité anti-inflammatoire observée pour l'extrait. Au cours de ce projet, 1'acide 3,4-di-O-caffeoylquinique a été rapporté pour la première fois à partir du Solidago canadensis. Également, les travaux de séparation ont mené à l'isolation de la quercétine et du $9 \alpha, 16 \xi$-dihydroxy-6-oxo-7,13-labdadièn-15,16- 
olide (solicanolide), un nouveau diterpène de la famille des labdanes. Ce nouveau composé a démontré une activité anticancéreuse intéressante sur les lignées cellulaires A-549, DLD1 et WS1. Cependant, les autres composés isolés se sont révélés inactifs.

Étant donné que les composés isolés dans l'extrait de fleurs du Solidago canadensis ne sont pas responsables de l'activité anti-inflammatoire observée pour l'extrait, il serait pertinent d'effectuer des travaux d'isolation supplémentaires. En ce qui concerne le solicanolide, le nouveau diterpène de type labdane isolé à partir du Solidago canadensis au cours de ce projet de maitrise, il serait intéressant d'en isoler à nouveau afin de compléter sa caractérisation. Grâce à la méthode des esters de Mosher et la diffraction des rayons X, la stéréochimie de la fonction hydroxyle en C-16 du solicanolide pourrait être élucidée. Par ailleurs, comme une activité anticancéreuse intéressante a été observée, la cytotoxicité de ce composé pourrait être évaluée sur davantage de lignées cellulaires. Également, il serait pertinent de faire une étude plus approfondie au niveau de l'activité biologique puisqu'il s'agit d'un nouveau composé et que par conséquent, son potentiel n'a pas été évalué de manière approfondie. 


\section{CHAPITRE VII}

BIBLIOGRAPHIE 


\section{Publications et livres}

Anthonsen, T., McCabe, P.H., McCrindle, R., Murray, R.D.H., 1969. Constituents of Solidago species I - The constitution and stereochemistry of diterpenoids from Solidago canadensis L. Tetrahedron 25, 2233-2239.

Anthonsen, T., McCabe, P.H., McCrindle, R., Murray, R.D.H., Young, G.A.R., 1970. Constituents of Solidago species II - Reactions of solidagenone, the major diterpenoid from Solidago canadensis L. Tetrahedron 26, 3091-3097.

Apáti, P., Szentmihályi, K., Balázs A., Baumann, D., Hamburger, M., Kristó, T.Sz., Szöke, É., Kéry, Á., 2002. HPLC analysis of the flavonoids in pharmaceutical preparations from canadian goldenrod (Solidago canadensis). Chromatographia 56, S-65-S-68.

Apáti, P., Szentmihályi, K., Kristo, Sz.T., Papp, I., Vinkler, P., Szoke, É., Kéry, Á.J., 2003. Herbal remedies of Solidago - correlation of phytochemical characteristics and antioxidative properties. Journal of Pharmaceutical and Biomedical Analysis 32, 10451053.

Apáti, P., Szentmihályi, K., Vinkler, P., Szoke, É., Kéry, Á., 2003. Nutritional value and phytotherapeutic relevance of solidaginis herba extracts obtained by different technologies. Acta Alimentaria 32, 41-51.

Arens-Corell, M., Okpanyi, S.N., 1990. Anti-inflammatory and analgesic actions of a model anti-rheumatic phytotherapeutic fixed combination drug: Phytodolor N. Planta Medica 56, 656-657.

Bohlmann, F., Fritz, U., King, R.M., Robinson, H., 1980. Sesquiterpene and diterpene derivatives from Solidago species. Phytochemistry 19, 2655-2661.

Boufford, D.E., "Flora of North America", Oxford University Press, New York, USA, 1993, vol. 20, p. 146-157.

Boulet, L.P., Becker, A., Bérubé, D., Beveridge, R., Ernst, P., 1999. Canadian asthma consensus report. Canadian Medicial Association Journal 161, 1-5.

Boyd, M.R., "Anticancer Drug Development Guide: Preclinical Screening, Clinical Trials, and Approval", Teicher, B. A., Ed., Humana Press: Totowa, NJ, 1997, pp. 23.

Bradette-Hébert, M.E., Legault, J., Lavoie, S., Pichette, A., 2008. A new labdane diterpene from the flowers of Solidago canadensis. Chemical and Pharmaceutical Bulletin 56, 82-84. 
Bryant, D., Nielsen, D., Tangley, L., "Les dernières forêts-frontière: écosystèmes et économies à la limite", Institut des ressources mondiales, Washington DC., United States, 1997, pp.42.

Chaturvedula, V.S.P., Zhou, B.-N., Gao, Z., Thomas, S.J., Hecht, S.M., Kingston, D.G.I., 2004. New lupane triterpenoids from Solidago canadensis that inhibit the lyase activity of DNA polymerase $\beta$. Bioorganic \& Medicinal Chemistry 12, 6271-6275.

Choi, S.Z., Sang, U., Bae, S.Y., Pyo, S.N., Lee, K.R., 2005. Immunobiological activity of a new benzyl benzoate from the aerial parts of Solidago virgaurea var. gigantea. Archives of Pharmacal Reasearch 28, 49-54.

Connolly, J.D., Hill, R.A., "Dictionary of terpenoids, Volume 1: Mono- and sesquiterpenoids", Chapman \& Hall, London, UK, 1991, pp. 653.

Connolly, J.D., Hill, R.A., "Dictionary of terpenoids, Volume 2: Di- and higher terpenoids", Chapman \& Hall, London, UK, 1991, pp. 1459.

Dufour, D., Pichette, A., Mshvildadze, V., Bradette-Hébert, M.E., Lavoie, S., Longtin, A., Laprise, C., Legault, J., 2007. Antioxidant, anti-inflammatory and anticancer activities of methanolic extracts from Ledum groenlandicum Retzius. Journal of Ethnopharmacology $111,22-28$.

Frère Marie-Victorin, "Flore Laurentienne", Troisième édition, Les Presses de 1'Université de Montréal, Montréal, Canada, 1995, pp.1093.

Gosset, P., Lassalle, P., Molet, S., Tonnel, A.B., 1998. Intéractions cellules inflammatoiresendothélium dans la réaction inflammatoire allergique, Revue française d'allergologie et d'immunologie clinique 38, 175-181.

Gross, S.C., Goodarzi, G., Watabe, M., 2002. Antineoplastic activity of Solidago virgaurea on prostatic tumor cells in a SCID mouse model, Nutrition and Cancer - An International Journal 43, 76-81.

Harvey, A., 2000. Strategies for discovering drugs from previously unexplored natural products. Drug Discovery Today 5, 294-300.

Kalemba, D., 1992. Phelolic acids in four Solidago species. Pharmazie 47, 471-472.

Kalemba, D., Thiem, B., 2004. Constituents of the essential oils of four micropropagated Solidago species. Flavour and Frangrance Journal 19, 40-43. 
Krepinsky, J., Herout, V., 1962. Isolation of terpenic compounds from Solidago canadensis L., Chemical Communications 27, 2459-2462.

Laberge et al., "Études des variations géographiques et annuelles de la fréquence de décès, d'hospitalisations et de visites à l'urgence pour cause d'asthme au Québec", Direction de la santé publique, RRSSS de Québec, Québec, Canada, 2000, pp.79.

Lemanske, R.F Jr., Busse, W.W., 2003. Asthma, The Journal of Allergy and Clinical Immunobiology $111,502-519$.

Leuschner, J., 1995. Anti-inflammatory, spasmolytic and diuretic effects of a commercially available Solidago gigantea herb. extract. Arzneimittel-Forschung Drug Research 45, 165 168.

Lu, T., Cantrell, C.L., Robbs, S.L., Franzblau, S.G., Fischer, N.H., 1998. Antimycobacterial matricaria esters and lactones from Asteraceae species. Planta medica 64, 665-667.

Lu, T., Menelaou, M.A., Vargas, D., Fronczek, F.R., Fischer, N.H., 1993. Polyacetylenes and diterpenes from Solidago canadensis. Phytochemistry 32, 1483-1488.

McCune, L.M., Johns T., 2002. Antioxidant activity in medicinal plants associated with the symptoms of diabetes mellitus used by the indigenous peoples of the North American boreal forest. Journal of Ethnopharmacology 82, 197-205.

Melzig, M.F., 2004. Goldenrod - A classical exponent in the uroligical phytotherapy. Wiener Medizinische Wochenschrift 154, 523-527.

Metzner, J., Hirschelmann, R., Hiller, K., 1984. Antiphlogistic and analgesic effects of leiocarposide, a phenolic bisglucoside from Solidago virgaurea L. Pharmazie 39, 869-670.

Moerman, D.E., "Native American ethnobotany", Third edition, Ed. Timber Press Inc., Portland, United States, 2000, pp. 536.

O'Brien, J., Wilson, I., Orton, T., Pognan, F., 2000. Investigation of the Alamar Blue (resazurin) fluorescent dye for the assessment of mammalian cell cytotoxicity. European Journal of Biochemistry 267, 5421-5426.

Ou, B., Hampsch-Woodill, M., Prior R.L., 2001. Development and validation of an improved oxygen radical absorbance capacity assay using fluorescein as the fluorescent probe. Journal of Agricultural and Food Chemistry 49, 4619-4626. 
Ou, B., Hampsch-Woodill, M., Flanagan, J., Deemer, E.K., Prior, R.L., Huang, D., 2002. Novel fluorometric assay for hydroxyl radical prevention capacity using fluorescein as the probe. Journal of Agricultural and Food Chemistry 50, 2772-2777.

Papp, I., Apáti, P., Andrasek, V., Blázovics, A., Balázs, A., Kursinszki, L., Kite, G.C., Houghton, P.J., Kéry, Á., 2004. LC-MS analysis of antioxidant plant phenoloids. Chromatographia 60, S93-S100.

Pauli, G.F., Poetsch, F., Nahrstedt, A., 1998. Structure assignment of natural quinic acid derivatives using proton nuclear magnetic resonance techniques. Phytochemical analysis 9 , 177-185.

Pfaller, M.A., Burmeister, L., Bartlett, M.S., Rinaldi, M.G., 1988. Multicenter evaluation of four methods of yeast inocolum preparation. Journal of Clinical Microbiology 26, 14371441.

Reznicek, G., Jurenitsch, J., Kubelka, W., Korhammer, S., Haslinger, E., Hiller, K., 1990. The first spectroscopically confirmed saponins from Solidago canadensis. Planta Medica 56,554 .

Reznicek, G., Jurenitsch, J., Plasun, M., Korhammer, S., Haslinger, E., Hiller, K., Kubelka, W., 1991. Four major saponins from Solidago canadensis. Phytochemistry 30, 1629-1633.

Reznicek, G., Jurenitsch, J., Freiler, M., Korhammer, S., Haslinger, E., Hiller, K., Kubelka, W., 1992. Isolation and structure elucidation of further new saponins from Solidago canadensis. Planta Medica 58, 94-98.

Schmeda-Hirschmann, G., Rodriguez, J., Astudillo, L., 2002. Gastroprotective activity of the diterpene solidagenone and its derivatives on experimentally induced gastric lesions in mice. Journal of ethnopharmacology 81, 111-115.

Thiem, B., Wesolowska, M., Skrzypczak, L., Budzianowski, J., 2001. Phenolic compounds in two Solidago L. species from in vitro culture. Acta Poloniae Pharmaceutica 58, 277-281.

To, W.K., Fothergill, A.W., Rinaldi, M.G., 1995. Comparative evaluation of macrodilution and alamar colorimetric microdilution broth methods for antifungal susceptibility testing of yeast isolates. Journal of Clinical Microbiology 33, 2660-2664.

Weber, E., 1998. The dynamics of plant invasions: a case study of three exotic goldenrod species (Solidago L.) in Europe. Journal of Biogeography 25, 147-154. 


\section{Sites internet}

http://www.mamr.gouv.qc.ca/regions/regi rura reus prod.asp:

Produits forestiers non ligneux: nouvelle économie forestière. Ministère des affaires municipales et des régions, Gouvernement du Québec.

Dernière mise à jour : 24-05-2007

http://www.mrnfp.gouv.qc.ca/forets/modernisation/modernisation-PGAF.jsp:

Report des plans généraux d'aménagement forestier et baisse de l'attribution de la matière ligneuse. Ministère des ressources naturelles et de la faune, Gouvernement du Québec.

Dernière mise à jour : 15-04-2008

http://www.pq.poumon.ca/diseases-maladies/asthma-asthme/asthma-asthme.php:

Asthme. Association pulmonaire du Québec.

Dernière mise à jour : 26-03-2008

http://plants.usda.gov/java/profile?symbol=SOCA6:

Natural resources conservation service, United States department of agriculture.

Dernière mise à jour : 27-03-2007 
CHAPITRE VIII

ANNEXES 
ANNEXE 1.

SPECTRE DE MASSE DU SOLICANOLIDE 


\section{HR-ESI-MS Solicanolide}

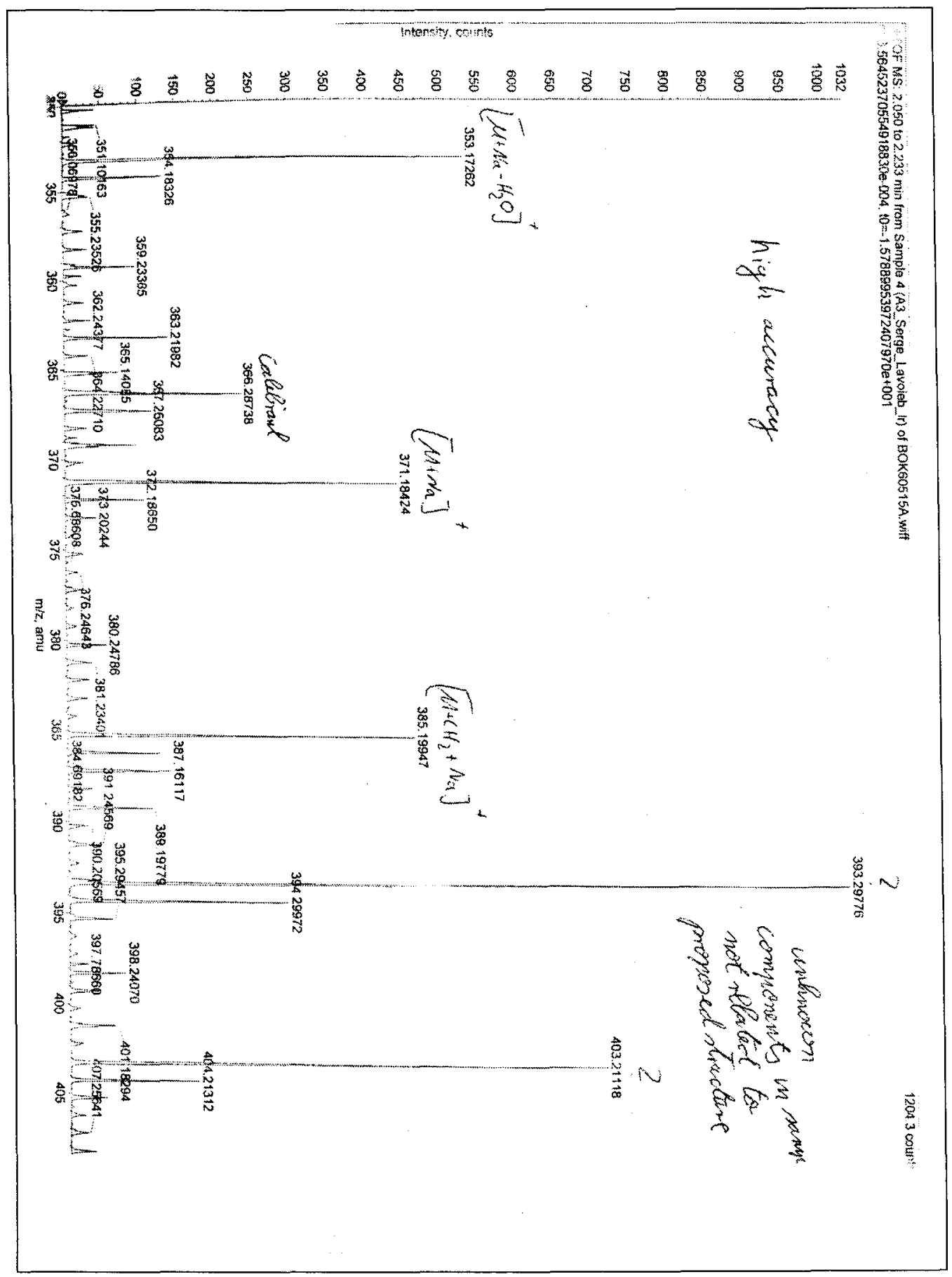

HR-ESI-MS $m / z 371.1834[\mathrm{M}+\mathrm{Na}]^{+}$ Calculé pour $\mathrm{C}_{20} \mathrm{H}_{28} \mathrm{O}_{5} \mathrm{Na}, 371.1842$ 
ANNEXE 2.

SPECTRES RMN DU SOLICANOLIDE 


\section{$\underline{{ }^{1} \text { H Solicanolide }}$}

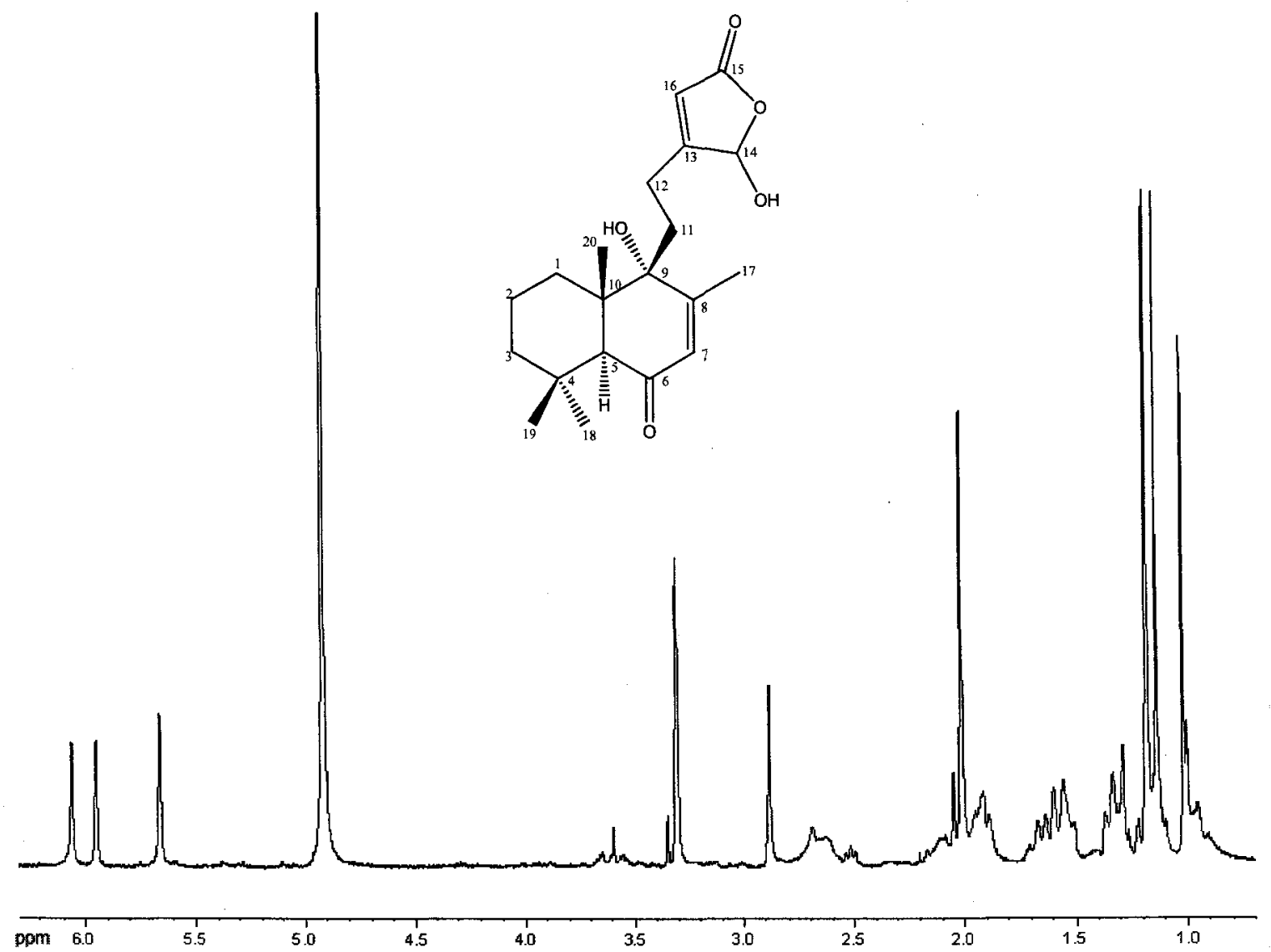

RMN ${ }^{1} \mathrm{H}(400 \mathrm{MHz}, \mathrm{MeOD}): \delta 6.06(1 \mathrm{H}, \mathrm{s}, \mathrm{H}-16), 5.95(1 \mathrm{H}, \mathrm{s}, \mathrm{H}-14), 5.66(1 \mathrm{H}, \mathrm{s}, \mathrm{H}-7)$, $2.88(1 \mathrm{H}, \mathrm{s}, \mathrm{H}-5), 2.65(1 \mathrm{H}, \mathrm{m}, \mathrm{H}-12), 2.11$ et $1.94(2 \mathrm{H}, \mathrm{m}, \mathrm{H}-11), 2.02(1 \mathrm{H}, \mathrm{s}, \mathrm{H}-17), 1.92$ et $1.57(2 \mathrm{H}, \mathrm{m}, \mathrm{H}-1), 1.66$ et $1.53(2 \mathrm{H}, \mathrm{m}, \mathrm{H}-2), 1.35$ et $1.19(2 \mathrm{H}, \mathrm{m}, \mathrm{H}-3), 1.18(1 \mathrm{H}, \mathrm{s}, \mathrm{H}-$ 19), 1.14 (1H, s, H-18), 1.02 (1H, s, H-20). 


\section{$\underline{{ }^{13} \text { C Solicanolide }}$}
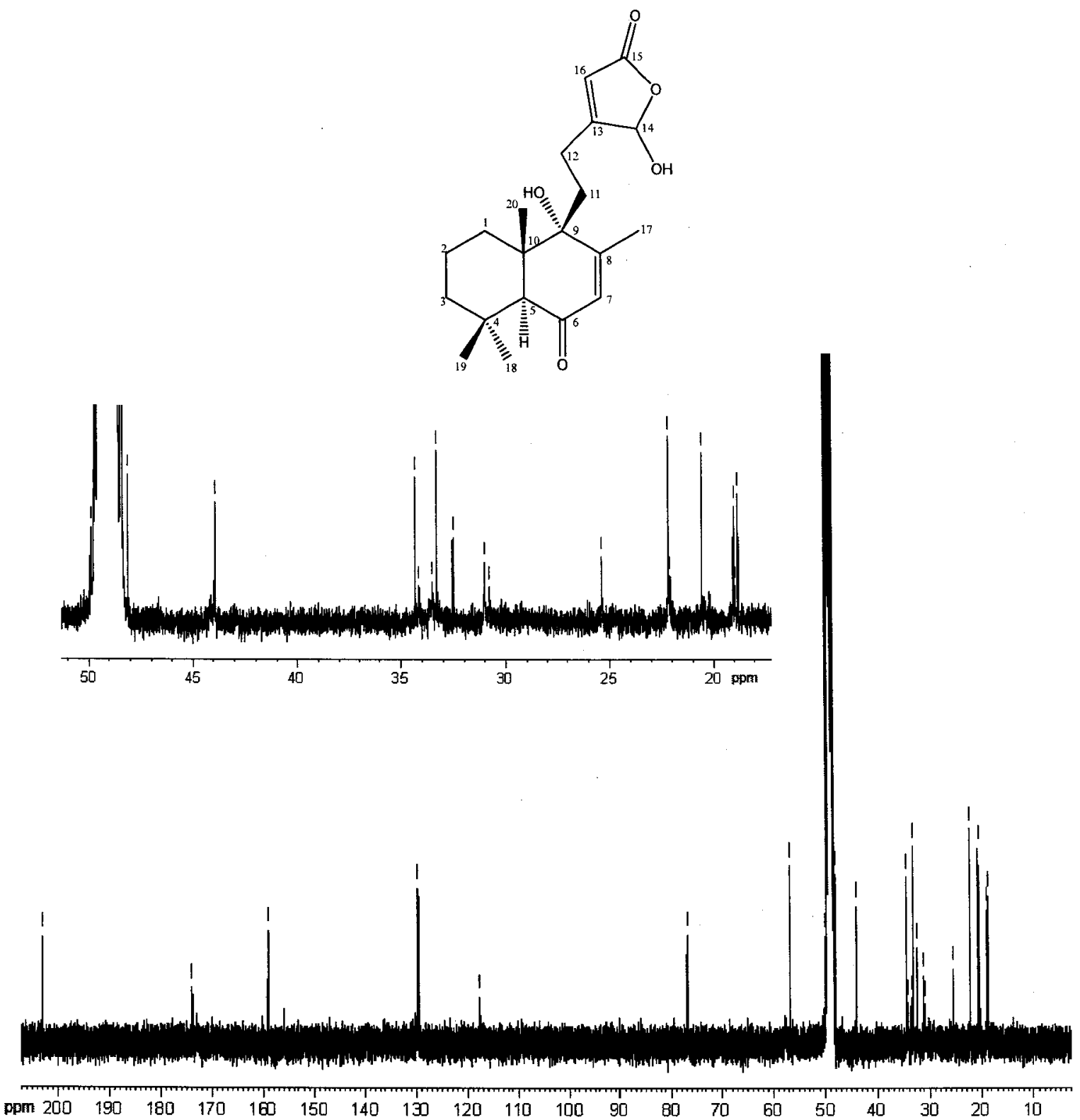

RMN ${ }^{13} \mathrm{C}(100 \mathrm{MHz}, \mathrm{MeOD}): \delta 202.9(6), 173.7(15), 172.8(13), 159.1(8), 129.6(7)$, 117.6 (14), $101.1(16), 76.7$ (9), $56.8(5), 48.1(10), 43.9$ (3), 34.3 (18), 33.3 (4), 32.6 (1), $31.0(11), 25.4(12), 22.2(19), 20.5(17), 19.0(2), 18.8(20)$. 


\section{COSY Solicanolide}
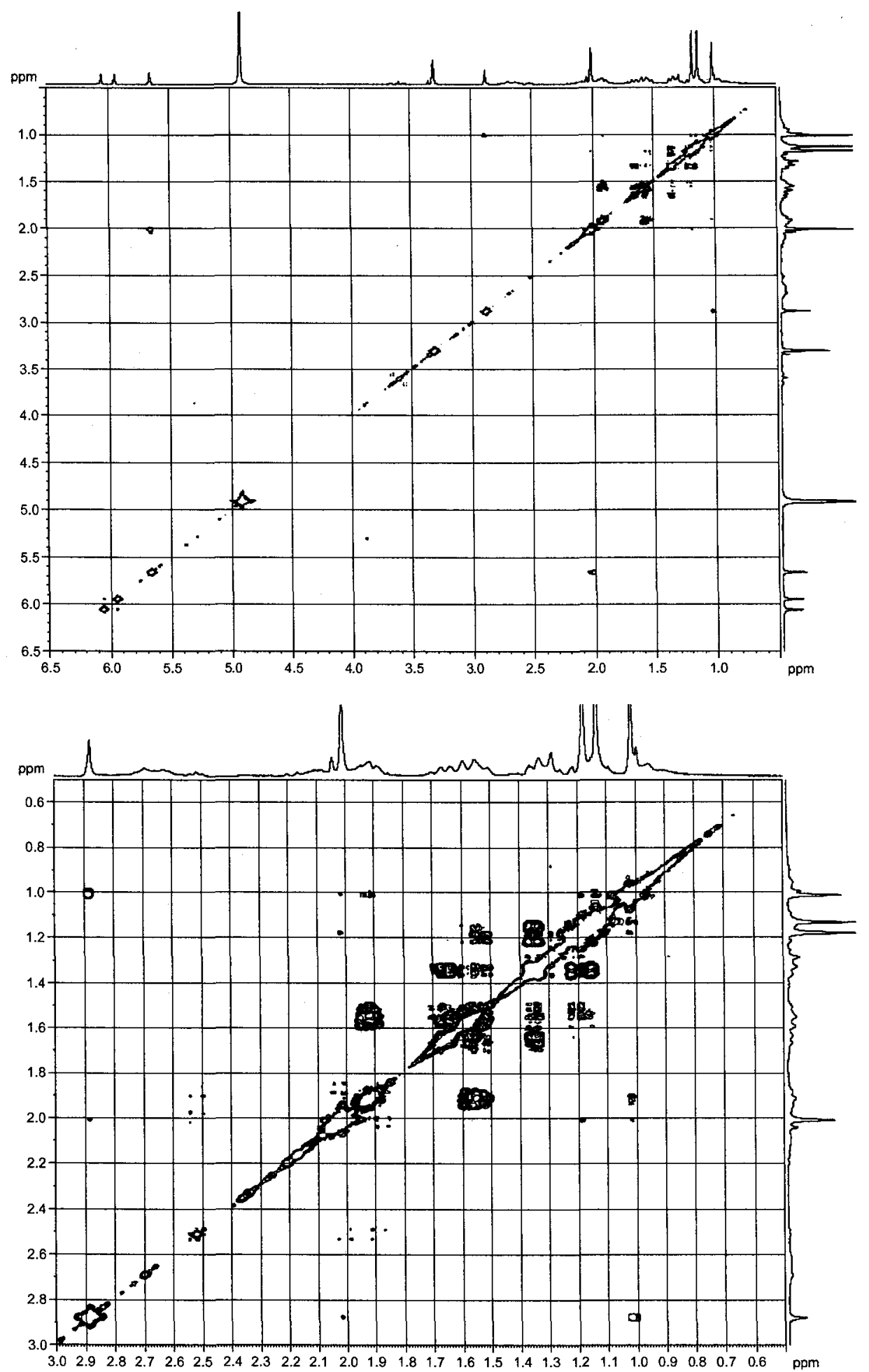


\section{HSOC Solicanolide}
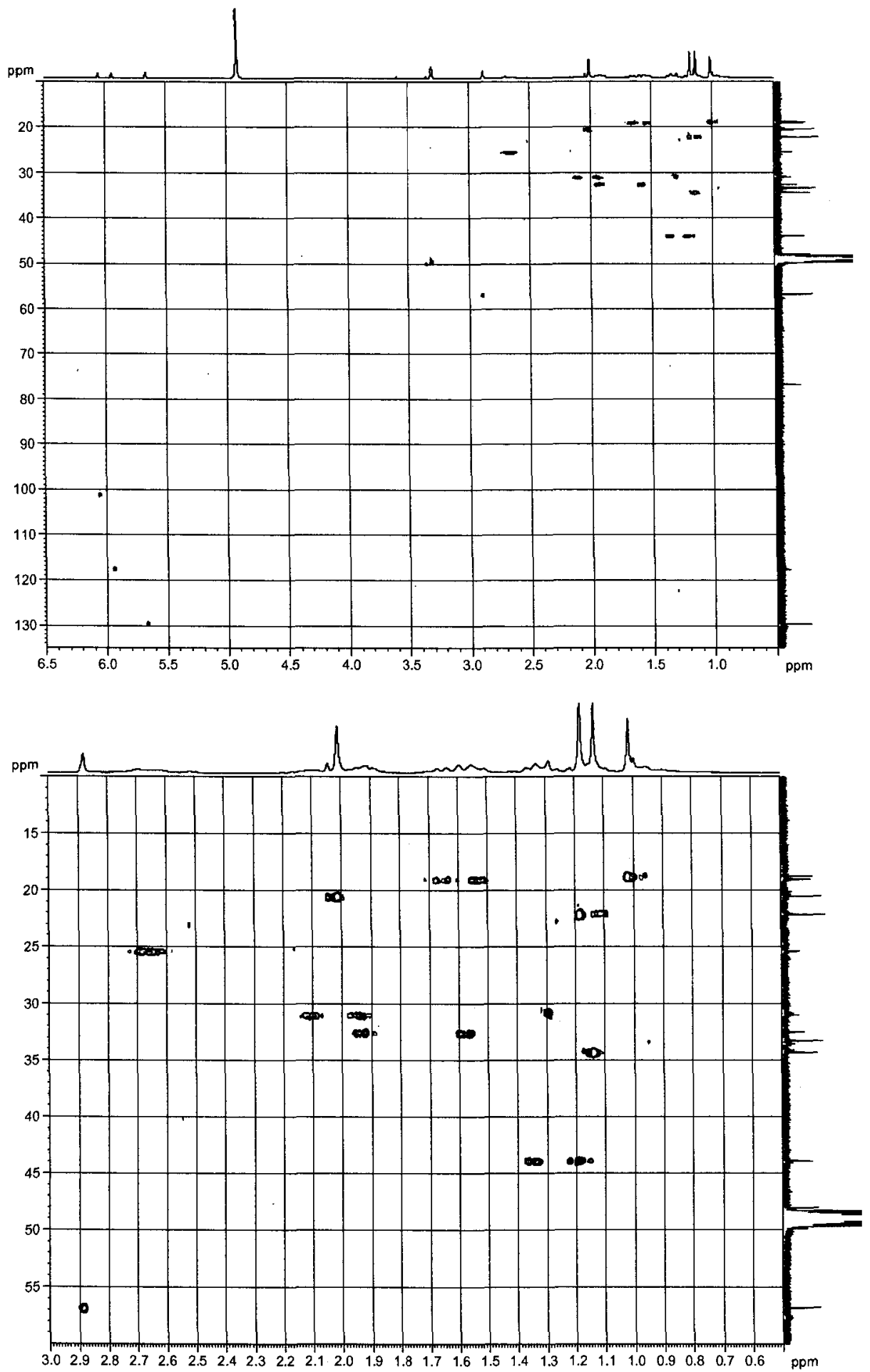


\section{HMBC Solicanolide}
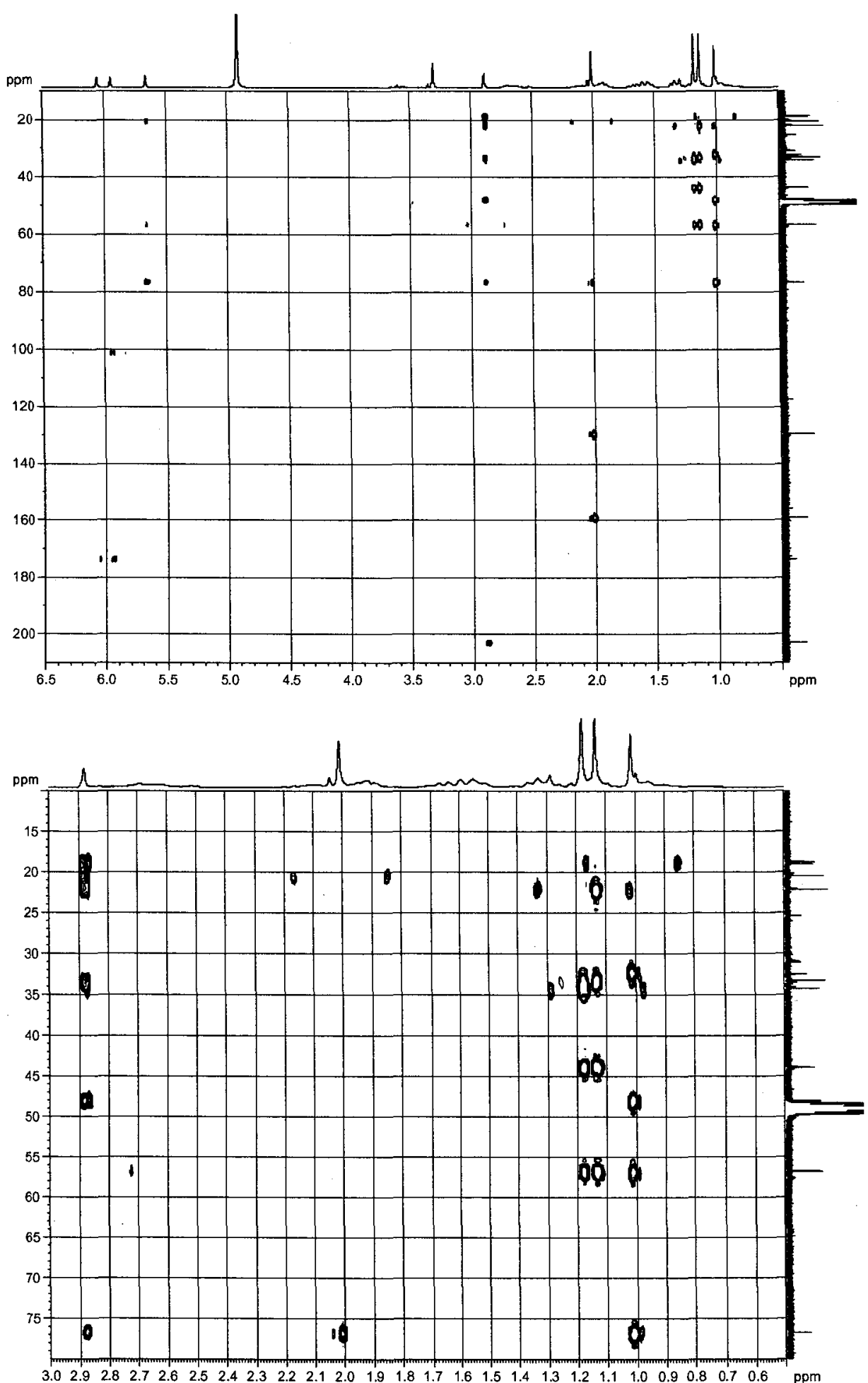
ANNEXE 3.

LISTE DES ABRÉVIATIONS 


\section{Liste des abbréviations}

$\begin{array}{ll}\text { ADN } & \text { Acide désoxyribonucléique } \\ \text { COSY } & \text { Correlation spectroscopy } \\ \text { DCFH-DA } & \text { 2,7-dichlorofluorescin-diacetate } \\ \text { HMBC } & \text { Heterocycle multiple bond correlation } \\ \text { HR-ESI-MS } & \text { High resolution electrospray isonisation mass spectra } \\ \text { HSQC } & \text { Heterocycle single quantum correlation } \\ \text { IC } 50 & \text { Concentration à laquelle il y a 50\% d'inhibition } \\ \text { LPS } & \text { Lipopolysaccharide } \\ \text { MeOD } & \text { Méthanol deutéré } \\ \text { NO } & \text { Nitric oxide } \\ \text { ORAC } & \text { Oxygen radical antioxidant activity } \\ \text { RMN } & \text { Résonance magnétique nucléaire } \\ \text { TE } & \text { Trolox equivalents }\end{array}$

